Bryant University

Bryant Digital Repository

$1-6-2019$

\title{
The Core, Periphery, and Beyond: Stock Market Comovements among EU and Non-EU Countries
}

Michael A. Goldstein

Joseph McCarthy

Bryant University, mccarthy@bryant.edu

Alexei G. Orlov

Follow this and additional works at: https://digitalcommons.bryant.edu/finjou

Part of the Finance and Financial Management Commons

\section{Recommended Citation}

Goldstein, Michael A.; McCarthy, Joseph; and Orlov, Alexei G., "The Core, Periphery, and Beyond: Stock Market Comovements among EU and Non-EU Countries" (2019). Finance Journal Articles. Paper 76.

https://digitalcommons.bryant.edu/finjou/76

This Article is brought to you for free and open access by the Finance and Financial Services Faculty Publications and Research at Bryant Digital Repository. It has been accepted for inclusion in Finance Journal Articles by an authorized administrator of Bryant Digital Repository. For more information, please contact dcommons@bryant.edu. 


\title{
The Core, Periphery, and Beyond: Stock Market Comovements among EU and Non-EU Countries
}

\author{
Michael A. Goldstein \\ Babson College \\ Joseph McCarthy \\ Bryant University \\ Alexei G. Orlov* \\ U.S. Securities and Exchange Commission
}

\begin{abstract}
Using linear and nonlinear correlations, copulas, quantile dependence and lower tail dependence, we find that (1) equity markets of the advanced European Union (EU) countries comove more closely with each other than with the peripheral economies, (2) comovements with non-EU countries are lower, (3) relative comovement structure before, during, and after the global financial crisis has been very stable, and (4) the level of comovements remained virtually the same between the crisis and post-crisis periods. Our results are robust to controlling
\end{abstract}

* Corresponding author: U.S. Securities and Exchange Commission, 100 F Street NE, Washington, DC 20549; Phone: 202-551-6434; E-mail: orlova@ sec.gov.

We thank conference participants at the 2016 Financial Management Association and our discussant Fernando Moreira, and two anonymous referees for immensely helpful comments. We also thank Andrew Patton and James P. LeSage for sharing their MATLAB codes for computing quantile dependence. The authors of this paper are responsible for any errors or omissions. The Securities and Exchange Commission, as a matter of policy, disclaims responsibility for any private publication or statement by any of its employees. The views expressed herein are those of the authors and do not necessarily reflect the views of the Commission or the authors' colleagues on the staff of the Commission. 
for Fama-French, U.S. and global risk factors, as well as monetary policy, market interest rates, exchange rates, and uncertainty.

Keywords: financial interdependence, comovements, European stock markets, PIIGS, Brexit, copulas, global financial crisis

JEL Classifications: C14, F30, F37, G10, G15

\section{Introduction}

The vote in the United Kingdom (UK) on June 23, 2016, to leave the European Union (EU) raised a variety of questions, including how and what EU membership affects. Although the UK's exit from the EU will affect a variety of trade and immigration issues, the Brexit vote (see, e.g., The Economist, 2016) also raises interesting questions about how Eurozone and EU membership affects comovements across not just the labor and goods markets but financial markets as well. This is especially pertinent since the UK is (still) a member of the EU but did not adopt the euro as its currency, unlike many other EU members such as Germany and France. As equity markets tend to aggregate the effects of goods, labor, foreign exchange, interest rates and capital markets, an important question is how EU membership (and nonmembership) affects equity market comovements among advanced and nonadvanced economies. Compounding these issues was the adoption of the euro as a common currency on January 1, 1999, which removed some diversification effects due to currency movements across Eurozone countries. Even so, notable differences remain across countries that use the euro.

In this paper, we examine the interrelationships among the core and periphery EU and Eurozone countries, and those of the UK and beyond. We try to answer three main research questions. First, how are comovements among European stock markets affected by the EU affiliation versus adoption of the euro? Second, do the European periphery economies' stock markets comove more or less with each other than with the stock markets of the core European countries? Third, how does the structure of stock market comovements change between tranquil and crisis periods?

Overall, we find that the core EU and Eurozone countries comove more with each other than any other group, and that the periphery EU and Eurozone countries comove more with the core than with each other. As the use of the euro and membership in the EU is removed, the stock market comovements become reduced. Interestingly, using a variety of statistical techniques, we find that the relative structure of comovements across countries prior to the crisis remained relatively constant before, during, and after the crisis. Notably, the absolute magnitude of the comovements increased during the financial crisis but did not diminish after the crisis. These effects continued to hold even after controlling for macroeconomic effects, Fama-French risk factors, or market controls as in Bekaert, Ehrmann, Fratzscher and Mehl (2014). 
This study contributes to two closely related strands of the literature-financial markets comovements and financial contagion (e.g., King and Wadhwani, 1990; Morck, Yeung and Yu, 2000; Kodres and Pritsker, 2002; Baele, 2005; Bekaert, Harvey and Ng, 2005; Bekaert, Hodrick and Zhang, 2009; Mendoza and Quadrini, 2010; Christoffersen, Errunza, Jacobs and Langlois, 2012; Bekaert, Ehrmann, Fratzscher and Mehl, 2014; Dungey and Gajurel, 2014; Caporin, Pelizzon, Ravazzolo and Rigobon, 2018). Although Solnik (1974) suggests that international investing adds substantial diversification benefits, more recent works by Chollete, de la Peña and Lu (2011), Christoffersen, Errunza, Jacobs and Langlois (2012), Fernández-Avilés, Montero and Orlov (2012), and others note that comovements in financial markets notably reduce the benefits of diversification. Aloui, Aïssa and Nguyen (2011) state that "correlations of global stock returns have increased in the recent periods as a result of increasing financial integration, leading to lower diversification benefits especially in the longer term" (p. 130), and note that "[a] number of past studies have reported the existence of significant linkages both between emerging and developed markets, and among emerging markets" (p. 131, emphases added). At the same time, recent events tied to the global financial crisis have affected different economies to differing degrees. These events have particularly affected highly indebted countries such as Portugal, Ireland, Italy, Greece and Spain (PIIGS) that were at the center of the Eurozone debt crisis, as compared with more developed economies such as France, Germany and the UK or the non-EU countries of Switzerland, South Africa, Japan and the United States. ${ }^{1}$

To examine these cross-country differences, we start with two core EU and Eurozone economies-France and Germany-and expand the sample by building concentric circles outward. We include five EU peripheral countries that adopted the euro-PIIGS - then expand to the UK, which is part of the EU but does not use the euro, and Switzerland, a European nation that is neither in the EU nor in the Eurozone but share languages and is contiguous with both France and Germany. We further expand our circle geographically to include (1) the United States, a G7 common-law country culturally similar to the UK, (2) South Africa, another commonlaw country culturally similar to the UK but smaller and likewise geographically distant, and (3) Japan, another large G7 country distant from the rest of the sample. This set of countries differ by EU and euro adoption as well as geographically, culturally, and by market size. ${ }^{2}$ We then use multiple statistical methods-from

\footnotetext{
${ }^{1}$ All of the PIIGS economies share an important feature that separates them from countries such as France or Germany-namely, high debt-to-gross domestic product (GDP) ratios, which manifested in domestic macroeconomic problems and which became a concern for other European economies. The data that we analyze support our categorization: stock market indices for Germany, France and the UK are at or above the Eurozone index (described in detail in Section 3), whereas Italy, Spain and the other PIIGS economies are distinctly below.
}

${ }^{2}$ Chui, Titman and Wei (2010) and many others examine the link between culture and international stock market returns. 
simple correlations, which assume a certain returns structure, to more complex and flexible techniques, such as copulas and quantile dependence-to examine how stock market comovements vary across these countries before, during, and after the global financial crisis, and control for a variety of common macroeconomic, market and risk factors.

Interestingly, we find that while all comovements increase during the global financial crisis, the comovements increase by about the same amount so that the relative overall comovement structure remains basically unchanged. This result is particularly surprising given the different levels from which the comovements started pre-crisis: the correlation between Greece and Ireland is about 0.36, while between France and Germany it is about 0.85 . Given the differences and the high level at which the France-Germany correlation is starting, it is surprising that the increase in the Germany-Spain comovement is the same as the increase in the France-Germany comovement from before to after the financial crisis. Even more interestingly, these increases during this time are of about the same magnitude as the increase for the Greece-Ireland comovement. As we move out of the Eurozone, the comovements of the UK and the non-EU countries have a similar structure during the crisis and post-crisis: the magnitude of the UK's comovement still is between Germany's and Switzerland's comovement. Overall, the structure is relatively similar for all countries besides Japan.

We also examine the effects of EU membership to see what the experience for the UK might be on completion of their leaving the EU. To do so, we examine parametric, nonparametric, and copula-based comovement tests on the Eurozone sample, the UK, and the four non-EU countries-Japan, South Africa, Switzerland, and the United States. We observe a lower degree of comovements of the EU members (including the UK) with South Africa and much lower for both Japan and, surprisingly, the United States. Switzerland's comovements with the EU members are stronger but still not as pronounced as the comovements of the EU's developed countries with each other. This finding can be accounted for by Switzerland's geographical proximity and trade ties with the EU, as well as similar macroeconomic fundamentals. Therefore, when the UK completes its exit from the EU, its stock market comovements with the EU members will likely be weakened. ${ }^{3}$

We also confirm previous work that found that the interdependence among the PIIGS equity markets is lower than that between each PIIGS market and either the most advanced EU nations (i.e., Germany, France, or the UK) or the non-EU nations. In fact, the advanced EU countries are characterized by more pronounced comovements with each other than the PIIGS markets with either the advanced EU

\footnotetext{
${ }^{3}$ The UK is subject to the Bank of England's monetary policy, not the policy of the European Central Bank (ECB). Thus, the presence of the UK in our sample serves as an independent check of a possible "euro currency factor" in pricing EU stocks. Since the results for the UK are similar to those for France and Germany, both in terms of comovements with PIIGS and with other advanced countries, the common currency alone is not the driving factor behind the results reported in this paper.
} 
economies or each other. Even during the financial crisis, despite their common high debt-to-GDP ratios and the common shock to these countries of the global financial crisis, we find higher interdependence across the advanced EU nations and lower with the less developed ones. ${ }^{4}$ These comovements also vary with EU membership. As an EU but not Eurozone nation, the UK has a high comovement with France and Germany, lower with Switzerland, and similar comovements with South Africa. The comovements are even less with either the United States or the PIIGS, and there is almost no comovement with Japan. ${ }^{5}$

Finally, we examine the possible effects of variation in common macroeconomic or market factors on our results. We control for these factors by orthogonalizing the individual countries' stock market returns to ECB monetary policy (as reflected in the ECB marginal lending rate), market interest rates (euro London Inter-bank Offered Rate [LIBOR] rate), the euro-dollar exchange rate, market uncertainty and risk (proxied by the volatility index [VIX]), as well as Fama-French, U.S. and global factors. Our main results continue to hold. Notably, the overall results in this paper are strongly robust to controlling for monetary policy, market interest rates, exchange rates, and risk and uncertainty, and are at best only partially affected by the FamaFrench, U.S. and global factors. Thus, in light of the contagion definition in Bekaert, Harvey and $\mathrm{Ng}$ (2005) and the empirical work by Boyson, Stahel and Stulz (2010) and Bekaert, Ehrmann, Fratzscher and Mehl (2014), among others, our results suggest that there was a financial contagion in the European equity markets during the global financial crisis, and that the consequences of this contagion (in the sense of greater comovements) are felt to this day. Consistent with several recent studies (see, e.g., Caporin, Pelizzon, Ravazzolo and Rigobon, 2018; Fratzscher, Lo Duca and Straub, 2018), we find that the U.S. linkages contributed to the spread of contagion in Europe.

Our paper makes several main contributions. First, we employ a wide array of methodologies that allow us to relate our findings to both the comovement and contagion literatures. Second, we document in a robust manner several stylized facts with respect to both cross-sectional and time series structures of comovements. Cross-sectionally, we find that the comovements among the core EU countries are

\footnotetext{
${ }^{4}$ These results hold even during the latter half of our sample during the market downturn and the global financial crisis, even though the less developed EU nations were dependent on bailouts at the time. Although the local effects varied, the global financial crisis had a common theme across Europe due to excessive leverage. Phylaktis and Xia (2009) point to global and regional shocks as well as financial linkages in the transmission of the financial crisis. The effects of deleveraging hit the PIIGS more than the developed markets, and the PIIGS looked to bailouts from the developed markets as they were tied to them through the euro and so could not just devalue their currency.

${ }^{5}$ These results are consistent with the finding of Christoffersen, Errunza, Jacobs and Langlois (2012) that comovements among emerging markets or between developed and emerging markets are not as pronounced as those among the developed markets. However, our more recent period also allows for new observations: while Christoffersen, Errunza, Jacobs and Langlois (2012) study a sample that ends in June 2009, our sample runs through September 2015, which allows us to compare comovements during the global financial crisis not only with the pre-crisis period but also with the post-crisis recovery. This comparison leads us to previously unreported, important results outlined in subsequent paragraphs.
} 
greater than the comovements between the core and the periphery, and that the coreperiphery comovements, in turn, are more pronounced than the comovements among the periphery economies. This relative comovement structure is remarkably stable over time and is not affected by macroeconomic and market factors. We also document that (1) following the onset of the global financial crisis, the comovement structure did not increase differentially but rather uniformly, and (2) post-crisis comovements remained virtually at the same level as they were during the global financial crisis. Thus, we find that while the recent financial crisis caused a permanent change in the level of stock market comovements, the relative comovement structure remained the same and was not affected by the crisis. ${ }^{6}$

Third, our paper also contributes to the literature as well as to the popular discourse by reporting a set of results for the UK that leads us to conclude that the UK's stock market comovements with the EU members will likely be weakened once Brexit is completed. The paper's additional methodological contribution is in establishing the robustness of the results using a wide array of methods for assessing stock market comovements, including linear and nonlinear correlations, copulas, quantile dependence and lower tail dependence, as well as using empirical marginal distributions and various distributional assumptions of the joint density function. Finally, the paper has important implications for portfolio management and, in particular, for financial diversification across the European equity markets.

The structure of the rest of the paper is as follows. The next section discusses the complementary methodologies used in the paper. Section 3 describes our data, Section 4 presents the main results, Section 5 investigates if common macroeconomic and market factors may drive our results, and Section 6 concludes.

\section{Methodology}

As outlined in Section 1, our research strategy is to select a set of countries that concentrically expand from the two most developed EU and Eurozone countries and employ increasingly complex statistical techniques to examine comovements among these countries over time. We then use these techniques on our sample countries to answer three main research questions. First, which matters more for the strength of stock market comovements-being part of the EU or part of the Eurozone? Second, should we expect tighter comovement among the peripheral Eurozone countries or between the core and the periphery? Third, did the structure of stock market

\footnotetext{
${ }^{6}$ Our finding of the unchanged relative structure of comovements in the wake of the recent financial crisis is in line with the results in Forbes and Rigobon (2002) for the earlier crises, which showed that the conventional correlation coefficients offer a biased measure of comovements since they are conditional on market volatility, but find only a small increase in unconditional correlation coefficients (referred to by Forbes and Rigobon as "interdependence") during the U.S. stock market crash of 1987, the peso devaluation of 1994, and the Asian crisis of 1997.
} 
comovements change with the onset of the financial crisis and during the post-crisis recovery?

Below, we further describe our selection of countries and methodologies.

\subsection{Country selection}

Our country sample starts with two core Eurozone countries, Germany and France. To this core, we add five peripheral and highly indebted Eurozone countries (PIIGS) that have been the focus of attention and that are also part of the EU. Next, we relax the requirement that the country use the euro and add the UK, a G7 country that is so far in the EU but not in the Eurozone.

Finally, we remove the requirement for EU membership and add four nonEU countries: Switzerland, the United States, South Africa, and Japan. These four non-EU countries were chosen to span similarities to the UK while providing both similarities and dispersion based on market size and geographical distance from the core EU/Eurozone countries of France and Germany. As Table 1 indicates, Switzerland (market cap $\$ 1.1$ trillion) is similar in size to France ( $\$ 1.8$ trillion) and Germany ( $\$ 1.5$ trillion), and borders EU countries without using the euro or being part of the EU.

To provide geographical diversity, we move out of Europe. We first add Japan (\$3.7 trillion), which has a market cap similar to the UK but is notably geographically distant. Next, we span size by including both the United States (\$18.7 trillion) and South Africa (\$0.6 trillion). The United States is a large northern hemisphere G7 market that shares a common heritage with the UK and parts of Europe both culturally and historically but is also geographically distant. South Africa is a smaller southern hemisphere market that provides some size similarity to the EU peripheral countries (its market cap is halfway between those of Italy and Spain) while still sharing a common cultural and historical heritage with the UK and parts of Europe.

Collectively, these countries provide both cross-country similarities and differences based on distance, size, culture, political affinity, EU membership, and use of a common currency (the euro).

\subsection{Empirical techniques: Correlations, copulas, quantile, and lower tail dependence}

\subsubsection{Overview of techniques used}

We employ a variety of statistical tests to examine comovements. We start by studying the more conventional measures of association, including Pearson, Spearman's rho and Kendall's tau correlations. Next, we turn to copula selection exercises to find out which copulas fit our data best, fit the selected copulas to the country returns data, and compute copula correlation coefficients. We rely on empirical marginal distributions when estimating the various copulas. 


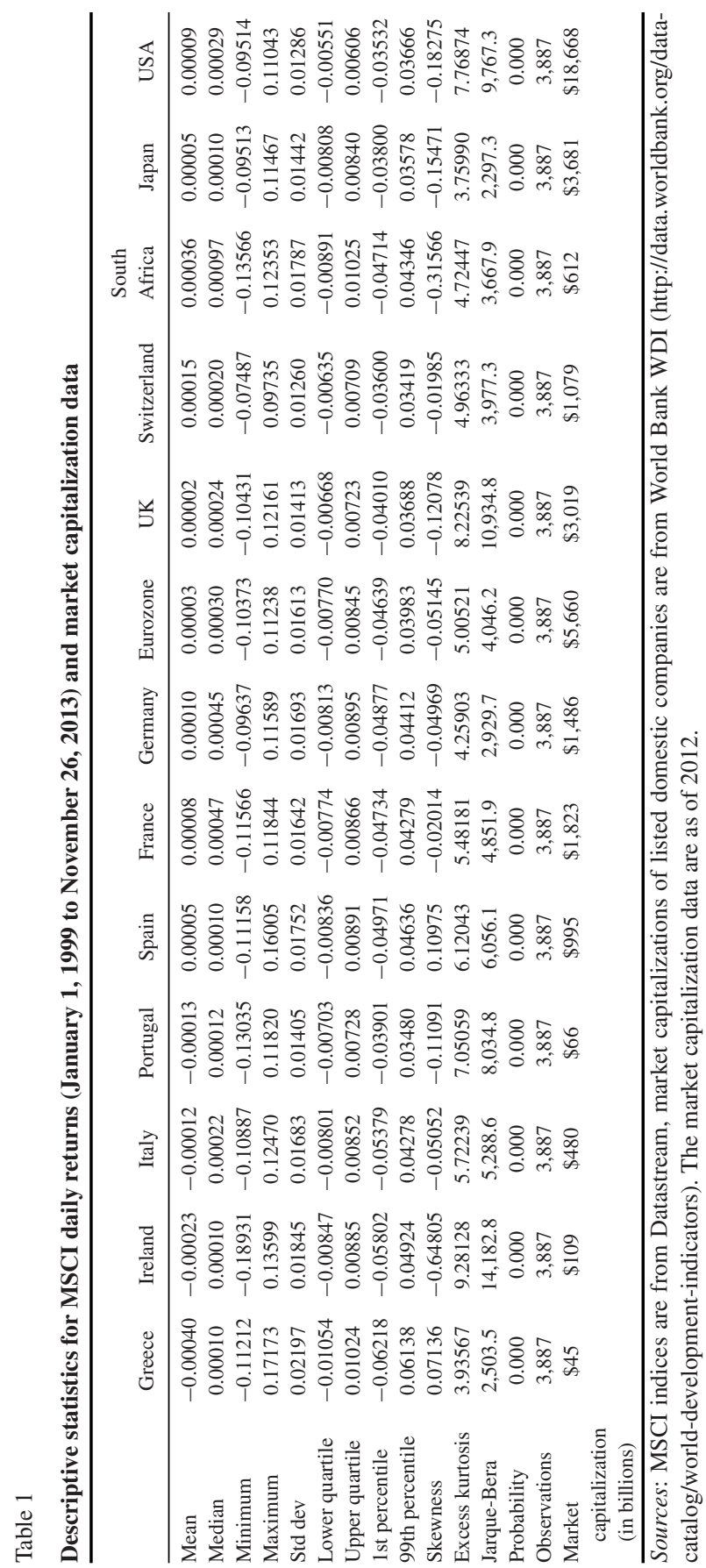


In addition to linear and nonlinear (or rank) correlations and copulas, we assess stock market interdependence using quantile dependence and tail dependence. Quantile dependence affords the flexibility of varying levels of correlation for different levels of returns. In addition to quantile dependence, tail dependence allows us to quantify comovements when the stock market returns have extremely high or extremely low values, and focusing on the lower tail dependence helps us contribute to the financial contagion literature. All of the dependence measures can be derived from the estimated copula parameters discussed in the Appendix. Put differently, the correlations, quantile dependence and tail dependence are different ways of assessing a dependence structure modeled by a specific copula. Below, we provide more details on the methodologies used.

\subsubsection{Correlations}

Similar to most of the existing literature on financial interdependence, we start our examination using simple correlations. Correlation is by far the most popular measure of dependence due to its inherent simplicity (e.g., Bekaert, Harvey and Ng, 2005). However, with simplicity come several potentially unattractive features of correlation. For example, while independence is a sufficient condition for uncorrelatedness, the latter does not imply independence. Importantly, the use of correlations requires the assumption of joint normality.

\subsubsection{Nonlinear measures of comovement}

Copulas. To overcome some of these issues, researchers recently have turned to nonlinear measures of comovement such as copula-based dependence measures, which are not dependent on such assumptions and can examine nonlinear effects. ${ }^{7}$ Copula methodology uses the information on both the marginal distributions and their dependence structure contained in any bivariate (or multivariate) distribution of a random vector, and isolates the description of the dependence structure from the marginal distributions. Unlike correlations, therefore, a copula approach is not dependent on distributional assumptions of joint normality that may be violated in the real world due to the well-documented nonlinearities of financial data (e.g., Favero and Giavazzi, 2002). Another attractive attribute of copulas is that they help disentangle the marginals from the dependence structure, thereby affording a more precise assessment of market comovements.

\footnotetext{
${ }^{7}$ The use of copulas to measure interdependence is becoming increasingly popular in the literature on financial market comovements: see, for example, Patton (2006), Bartram, Taylor and Wang (2007), Rodriguez (2007), Aloui, Aïssa and Nguyen (2011, 2013), Chollete, de la Peña and Lu (2011), Herrera and Eichler (2011), Christoffersen, Errunza, Jacobs and Langlois (2012) and Reboredo and Ugolini (2015), among others.
} 
We fit five copulas (Gaussian Normal, Student's $t$, and Archimedean copulasClayton copula, Gumbel copula and Frank copula) to our data on index returns. Technical preliminaries on copulas and a review of these five copulas are provided in the Appendix. These five copulas have been used in the comovements literature most frequently. ${ }^{8}$ In Section 4, we examine several metrics, statistics, and simulations to determine which copula(s) fit our data best.

Rank correlations. We use rank correlations to circumvent potential problems associated with simple correlations, such as their inability to carry much information about joint distributions or to capture nonlinear interdependence. Rank correlations are nonparametric measures of dependence or, more precisely, concordance. In particular, we compute two such measures: Kendall's tau and Spearman's rho. One of the most attractive features of these measures is their dependence on the copula of the random variables and not on the marginal distributions. Since copulas are immune to monotonic transformations of random variables, this property allows Kendall's tau and Spearman's rho to capture nonlinear dependence. (See the Appendix for definitions of Kendall's tau and Spearman's rho.)

Quantile dependence. The degree of interdependence when returns are low (e.g., during a crisis) can be different from that for average or high returns. To explore this possibility, we also study quantile dependence, which allows us to observe how correlation changes from one quantile to the next. Specifically, we follow Patton (2012) and, for each pair of variables, measure the probability of one variable lying below (above) its $i$ th quantile, given that the other variable also lies below (above) its $i$ th quantile. Thus, this measure helps shed light on tail dependence (see, e.g., Patton, 2006) and complements tail dependence coefficients used in the literature (e.g., Herrera and Eichler, 2011; Christoffersen, Errunza, Jacobs and Langlois, 2012). ${ }^{9}$

Tail dependence. In addition, investors and policy makers are particularly concerned with extreme negative comovements, which the empirical literature typically

\footnotetext{
${ }^{8}$ This study focuses on comovements of returns. The existing research that studied volatility have used some of these copulas in conjunction with GARCH models (e.g., Bartram, Taylor and Wang, 2007; Aloui, Aïssa and Nguyen 2011, 2013). In this paper, we opt against restricting the power of copulas by imposing a GARCH model on the data; Aloui, Aissa and Nguyen (2013) perform a robustness check using raw returns and report that results are not immune to moving from GARCH-filtered to raw returns. Christoffersen, Errunza, Jacobs and Langlois (2012) and Lucas, Schwaab and Zhang (2014) use skewed $t$ copula, which allows for the possibility of an asymmetric dependence. Other variations include the symmetrized Joe-Clayton (Patton, 2006) and the factor copula (Oh and Patton, 2017).

${ }^{9}$ Tail dependence coefficients measure the probability of two variables concurrently assuming extremely positive or negative values. One could argue that quantile dependence offers a more comprehensive approach to measuring dependence, as compared with tail dependence, as it explores all realizations of random variables. Although focusing on extremely negative returns may be sufficient in a pure contagion context, a comovements study, such as ours, dictates that we include in our analysis the entire range of returns.
} 
associates with contagion events (e.g., Rodriguez, 2007; Aloui, Aïssa and Nguyen, 2011). To zero in on the extreme negative comovements, for each pair of stock markets we report a copula-based lower tail dependence. (Our lower tail dependence measure is also defined and discussed in the Appendix.)

\subsection{Common factors}

We also investigate which common macroeconomic and market factors may have contributed to the observed stock market comovements, both cross-sectionally and over time. To this end, we orthogonalize the stock market returns using the following factors: ECB monetary policy, market interest rates, risk and uncertainty (as proxied by VIX), euro-dollar exchange rate, Fama-French risk factors, and U.S. and global market factors. We then apply our statistical techniques to the orthogonalized returns. This approach is in the spirit of Boyson, Stahel and Stulz (2010) and Bekaer, Ehrmann, Fratzscher and Mehl (2014) and relies on the literature's most frequently used definition of contagion from Bekaert, Harvey and $\mathrm{Ng}$ (2005), which views contagion as an increase in comovements over and above what would be expected based on the changes in economic fundamentals. Thus, this approach allows us to place our study not only within the comovements literature but also within the financial contagion research.

\section{Data}

We use daily returns since the adoption of the euro (January 1,1999) on stock market indices for the five PIIGS economies, three European developed economies (France, Germany and the UK), as well as the aggregate index for the entire Eurozone and four non-EU countries (Switzerland, South Africa, Japan, and the United States). Our paper analyzes comovements of the nine EU stock market indices and the four non-EU stock market indices by studying all 78 pairwise correlations as well as $156(2 \times 78)$ copula-based dependence measures (as will be seen below, of the five copulas examined, two fit well). The MSCI indices, which were downloaded from Datastream, are U.S.-dollar price indices that measure the overall price performance of the respective markets and do not include dividends. ${ }^{10}$ A return on each index

\footnotetext{
${ }^{10}$ Datastream mnemonics of the time series used are as follows: MSPORD\$ (Portugal), MSITAL\$ (Italy), MSEIRE\$ (Ireland), MSGDEE\$ (Greece), MSSPAN\$ (Spain), MSFRNC\$ (France), MSGERM\$ (Germany), MSUTDK\$ (UK), MSEURI\$ (Eurozone), MSSWIT\$ (Switzerland), MSSARF\$ (South Africa), MSJPAN\$ (Japan), MSUSAM\$ (the United States). The Eurozone index warrants additional description. The base date for the index is December 31, 1996. After November 30, 2007, this index transitioned to the MSCI EMU (European Economic and Monetary Union) Large Cap Index. The index is a free float-adjusted capitalization-weighted index that measures the equity market performance of countries within EMU and consists of 10 country indices-Austria, Belgium, Finland, France, Germany, Ireland, Italy, the Netherlands, Portugal and Spain. For a wealth of additional details with regard to construction of MSCI indices (such as index constituents, weights, etc.), see https://www.msci.com/eqb/methodology/meth_docs/MSCI_Feb2015_GIMIMethodology.pdf
} 
represents the sum of its constituents' free float-weighted market capitalization returns. Because of Greece's reclassification by MSCI, the country's MSCI time series ends on November 26, 2013. For consistency and due to the importance of Greece during the events of the global financial crisis, the main sample studied in the paper is January 1, 1999 to November 26, 2013. However, as a robustness check, we also extend the sample to September 24, 2015 (while excluding Greece) and report no changes in the results.

Although descriptive statistics reported in Table 1 show that the stock returns for all series are nonnormal, that is not an unusual result for time series of returns on major markets. There is a difference between the mean and median values for all of the series (including the very large stock markets of the United States, the UK and Germany), indicating that the distribution of each of the data series is asymmetrical. In addition, all of the data series have a high Jarque-Bera value and excess kurtosis values exceeding the value of 0 . However, for most countries including the PIIGS, the departure from a normal distribution is not considerable.

\section{Main results}

\subsection{Copula selection}

To determine which copulas fit our data best, we study several metrics and statistics as well as conduct simulations. First, we test the significance of the copulas' parameters on all of our time series, those of both EU and non-EU countries. The degrees of freedom parameter $(v)$ for the $t$ copula and the $\theta$ parameter for Clayton, Frank and Gumbel copulas are all significant at the $1 \%$ level. Second, we compute Akaike information criterion and Schwarz Bayesian criterion. According to these criteria, the $t$ copula produces the best fit, while the fit based on the Archimedean copulas (Clayton, Frank and Gumbel) is far inferior. ${ }^{11}$

Third, to further compare $t$, Clayton, Frank and Gumbel copulas with one another as well as with the Normal copula, Figure 1 plots empirical copulas based on the original data against rank-based simulations for each of the five theoretical copulas under consideration (for the details of this procedure, see Chvosta, Erdman and Little, 2011). The closer the graph to the $45^{\circ}$ line, the better the particular copula fits our data. Visual inspection of Figure 1 reveals that the $t$ and Normal copulas provide a better fit than the other three alternatives. Finally, also following Chvosta, Erdman and Little (2011), we quantify the conclusions drawn from Figure 1 by comparing percentiles for copulas based on the original data and simulated Clayton, Frank, Gumbel, Normal and $t$ copulas in Table 2. Specifically, our metric based on

(MSCI Global Investable Market indices Methodology) and https://www.msci.com/eqb/methodology/ meth_docs/MSCI_Apr15_IndexCalcMethodology.pdf (MSCI Index Calculation Methodology). These indices are also available through other data providers such as Bloomberg.

11 Tabulated results are available on request. 
(A) Normal and $t$ copulas

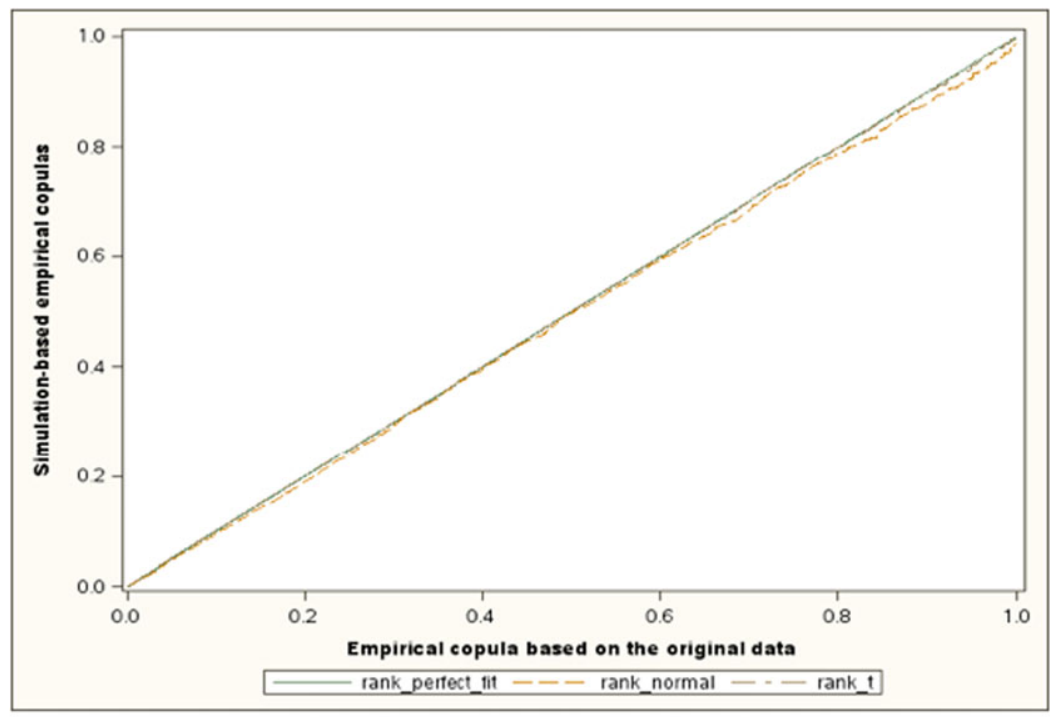

(B) Archimedean copulas (Clayton, Frank, and Gumbel)

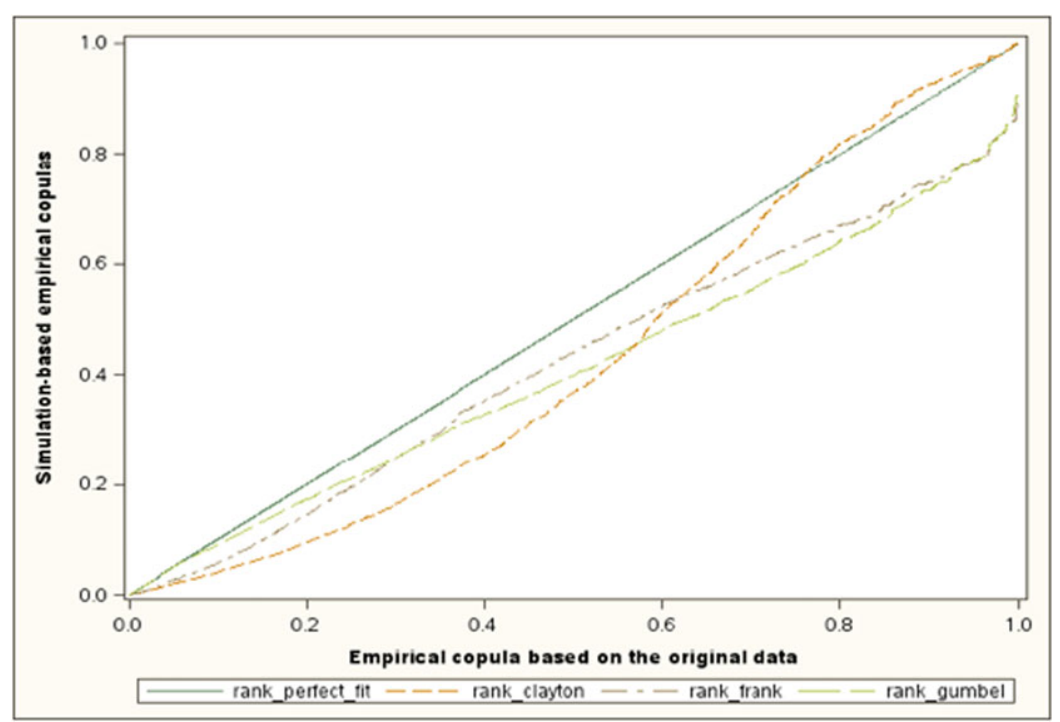

Figure 1

Choosing a copula: Empirical copulas based on the original data and simulated Clayton, Frank, Gumbel, Normal, and $t$ copulas, January 1, 1999 to November 26, 2013 
Table 2

Copula selection: Percentiles for empirical copulas based on the original data and simulated Clayton, Frank, Gumbel, Normal, and $t$ copulas

$\sum\left(C_{t}^{O}-C_{t}^{S}\right)^{2} \equiv$ sum of squared differences between the empirical copulas based on the original data and simulations.

\begin{tabular}{lcccccc}
\hline Percentile & Original data & Clayton & Frank & Gumbel & Normal & $t$ \\
\hline 0.05 & 0.01742 & 0.00664 & 0.00756 & 0.01649 & 0.01511 & 0.01740 \\
0.10 & 0.03643 & 0.01374 & 0.01717 & 0.03526 & 0.03114 & 0.03641 \\
0.15 & 0.05500 & 0.02198 & 0.02885 & 0.05404 & 0.05107 & 0.05519 \\
0.20 & 0.07860 & 0.03114 & 0.04236 & 0.07305 & 0.07259 & 0.07854 \\
0.25 & 0.10197 & 0.04145 & 0.05908 & 0.09160 & 0.09595 & 0.10190 \\
0.30 & 0.12970 & 0.05542 & 0.08015 & 0.11404 & 0.12205 & 0.12938 \\
0.35 & 0.15697 & 0.06938 & 0.10602 & 0.13694 & 0.14747 & 0.15709 \\
0.40 & 0.18584 & 0.08496 & 0.13144 & 0.16121 & 0.17449 & 0.18571 \\
0.45 & 0.21677 & 0.10579 & 0.16258 & 0.18617 & 0.20632 & 0.21662 \\
0.50 & 0.25195 & 0.12892 & 0.19624 & 0.21159 & 0.24319 & 0.25189 \\
0.55 & 0.29010 & 0.15480 & 0.23540 & 0.24044 & 0.28143 & 0.29013 \\
0.60 & 0.32493 & 0.18663 & 0.27639 & 0.27273 & 0.32196 & 0.32494 \\
0.65 & 0.36778 & 0.22578 & 0.32242 & 0.30730 & 0.36593 & 0.36776 \\
0.70 & 0.42209 & 0.27639 & 0.36936 & 0.34074 & 0.41699 & 0.42203 \\
0.75 & 0.47709 & 0.34074 & 0.42043 & 0.38264 & 0.47126 & 0.47722 \\
0.80 & 0.54148 & 0.41539 & 0.47401 & 0.43165 & 0.53538 & 0.54156 \\
0.85 & 0.61182 & 0.52943 & 0.53355 & 0.49210 & 0.60408 & 0.61163 \\
0.90 & 0.70005 & 0.65629 & 0.59583 & 0.55370 & 0.68583 & 0.70025 \\
0.95 & 0.79835 & 0.81841 & 0.66888 & 0.64071 & 0.78956 & 0.79826 \\
1.00 & 0.99863 & 0.99977 & 0.91482 & 0.94229 & 0.99015 & 0.99863 \\
$\sum\left(C_{t}^{O}-C_{t}^{S}\right)^{2}$ & & 0.18087833 & 0.07707843 & 0.10418573 & 0.00118056 & 0.00000032 \\
\hline & & & & & & \\
& & & & & & \\
& & & & & &
\end{tabular}

Chvosta, Erdman and Little (2011) is the sum of squared differences between copulas based on the original data and simulations, which is reported in the last row of Table 2. In line with the results from Figure 1, we find that the $t$ copula yields the smallest sum of squared differences $(0.00000032)$ and that the Normal copula produces the second smallest value (0.00118056). Thus, our copula selection exercises suggest that the $t$ and Normal copulas fit the data better than the alternatives. Accordingly, in our subsequent analysis we will confine our attention to these two copulas. ${ }^{12}$

\subsection{Full sample}

\subsubsection{Linear and nonlinear correlation results}

Given that the Gaussian Normal and Student's $t$ distributions fit our data well, we begin by using traditional correlation measures of association. Table 3 shows a

\footnotetext{
${ }^{12}$ When we compare the pre-crisis period with crisis and recovery, $t$ and Normal copulas continue to provide the best fit in both subsamples. Thus, unlike in Okimoto $(2008,2014)$ and Chollete, Heinen and Valdesogo (2009), the underlying dependence structure remains unchanged in our sample.
} 


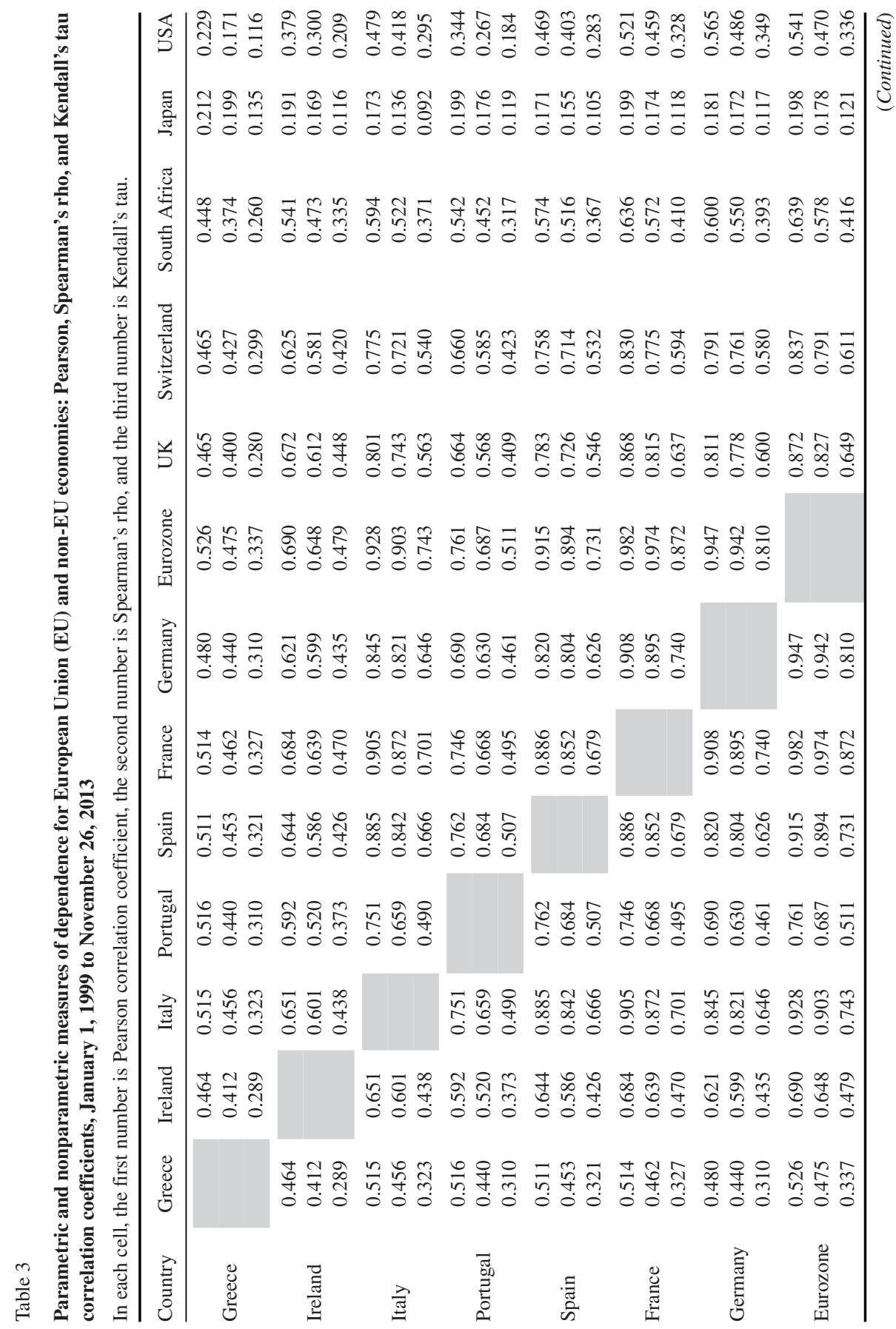




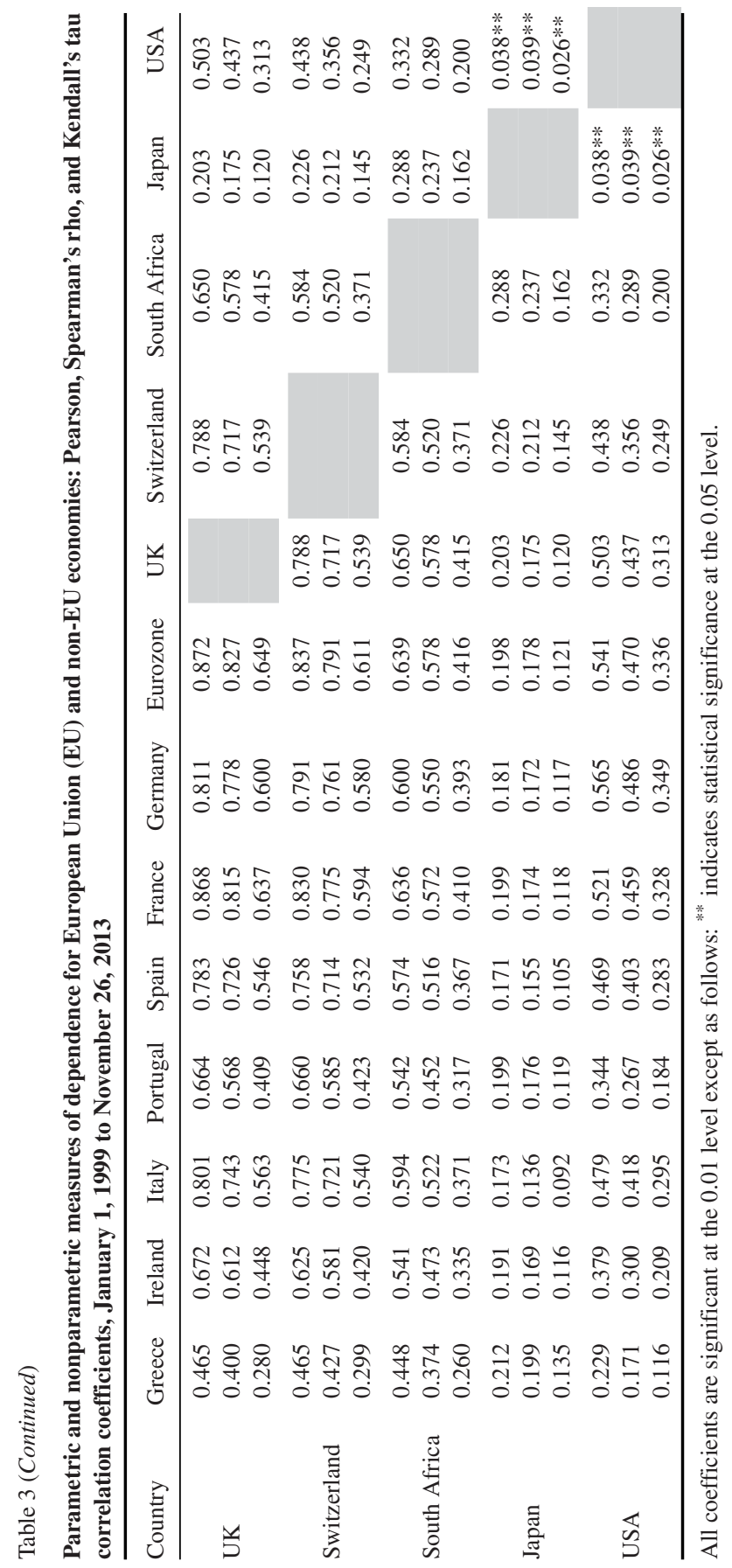


comparison of three traditional measures of association: Pearson, Spearman's rho and Kendall's tau correlation coefficients over the entire main sample period. The first part of Table 3 contains the results for the EU-that is, the Eurozone countries and the UK (as things currently stand) - while the second part of Table 3 repeats the results for the UK alongside the results for the non-EU countries (as things may become if or when the UK follows through on its Brexit vote). All values in the table are statistically significant at the $1 \%$ level, except the United States-Japan that are significant at the $5 \%$ level. The top value in each cell is the Pearson correlation coefficient, which is the most widely used measure of association. The Pearson coefficient consistently has the highest value reported in Table 3. The middle value is the Spearman's rho, which is a measure of association by ranks. In our study, the value of Spearman's rho is typically 2-5\% lower than the respective corresponding value of Pearson correlation. At the bottom of each cell, we report the values of Kendall's tau, which is a measure of concordance. In Table 3, these values are typically 10-15\% below the value of the Pearson correlation coefficients.

The comovements of the non-EU countries' stock markets with each other and with the EU members are weaker than the comovements of the EU countries with each other. In particular, the results for Switzerland (which borders on both France and Germany and has large trade with both) are particularly informative. The results for Switzerland, while similar to the UK, are uniformly smaller than the results for the UK (except for Greece, where they are the same) and for the other EU countries. The UK-Italy (Pearson correlation of 0.801) and Switzerland-Italy (Pearson correlation of 0.775 ) values are particularly indicative, as Switzerland (non-EU) borders Italy (EU), while the UK (EU) does not. Similar results for non-EU Switzerland and the bordering countries of France and Greece show that the UK has higher comovements with EU countries that border Switzerland than does Switzerland. These consistently weaker comovements suggest that even in the presence of trade interdependence, stock market comovements of a non-EU country with EU members are weaker than comovements of EU countries with each other, and may provide a glimpse into what is likely to happen to the UK stock market comovements with the EU member nations if and when the UK follows through on its decision to leave the EU.

\subsubsection{Copula results}

Table 4 reports the copula correlation coefficients based on fitting a $t$ distribution copula (Panel A) and Gaussian Normal copula (Panel B) to the country return data over our main time period of January 1, 1999 to November 23, 2013 (when Greece left the sample). The copula procedure is a measure of dependence by ranks, but it is also a measure that is dependent on the specification of the underlying data distribution that is used to transform the data to a $[0,1]$ uniform distribution. Thus, although the copula procedure has the advantage of working with nonlinear data transformations (e.g., returns, log-returns, etc.), the procedure may produce different values depending on the assumed underlying data distribution. Additionally, only the 


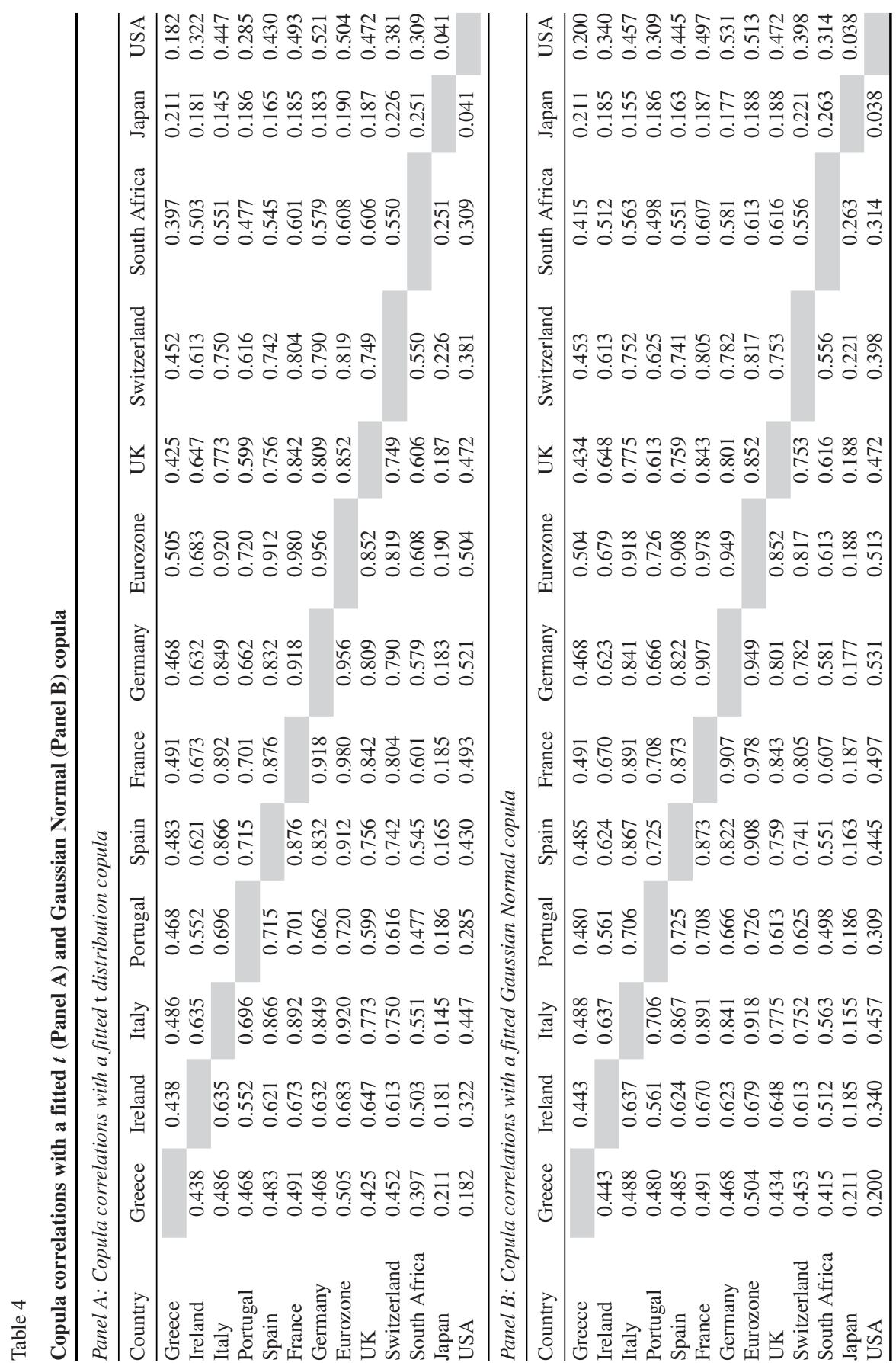


Pearson correlation maintains the time dimension of the different paired data series being considered. In reviewing the copula correlation values in Panel A of Table 4, we note that with the exception of Germany, all of the values are approximately midway between the Pearson and Spearman's correlation coefficients reported in Table 3. In the case of Germany, the copula correlations are occasionally $1 \%$ above the Pearson values.

Correlations reported in Panel B of Table 4 rely on a fitted Gaussian Normal copula. This panel reports values that are only slightly different from our results in Panel A. Thus, although distributional assumptions of the joint density function make a difference, this difference is rather small for the data set that we examine. This result is consistent with our findings in connection with the copula selection exercisesnamely, that the $t$ copula fits the data best, with the Normal copula being a close second. ${ }^{13}$ The results for the UK and Switzerland demonstrated in Table 3 continue to carry over here: The UK (a member of the EU thus far) has higher comovement copula results with Switzerland's neighbors than does Switzerland.

Our main results are further reflected in unreported (but available on request) scatterplots, including a scatterplot based on $t$ copulas and empirical marginal distributions. We observe that the interdependence among the PIIGS economies is not as strong as between each of the PIIGS and the more fiscally sound European economies-Germany, in particular, and the Eurozone, in general. This latter interdependence, in turn, is not as pronounced as the comovements between the core Eurozone markets. ${ }^{14}$

\subsubsection{Quantile dependence}

Another way of examining interdependence between markets is to study quantile dependence. This measure allows for varying levels of correlation under different market conditions, such as extremely high or extremely low returns. Figure 2 plots quantile dependence for several pairs of countries. Similar to Patton (2012), the horizontal axis measures quantiles of returns, and the vertical axis measures the probability of one return being below (above) its $i$ th quantile, conditional on the other return also being below (above) its $i$ th quantile. Therefore, the further away the graph is from a straight line, the more variation in dependence across quantiles one can observe. Conversely, if a graph is close to a straight line, the correlation is largely constant across quantiles. ${ }^{15}$

\footnotetext{
${ }^{13}$ As the Archimedean copulas did not perform well on our goodness-of-fit tests, we do not report their results here.

${ }^{14}$ As a robustness check, we extend the sample to September 24,2015 , to see if our results hold with the inclusion of the most recent data. Since the MSCI index for Greece is available only through November 26, 2013 (the limiting date for our main sample), we exclude Greece for the purposes of this exercise. Our results are virtually intact with the expansion of the sample.

${ }^{15}$ Thus, this methodology sheds light on tail dependence in the comovements of returns. We use copulas to examine the possibility of tail dependence in subsection 4.5 .
} 
(A) Quantile dependence: Greece vs. PIIGS
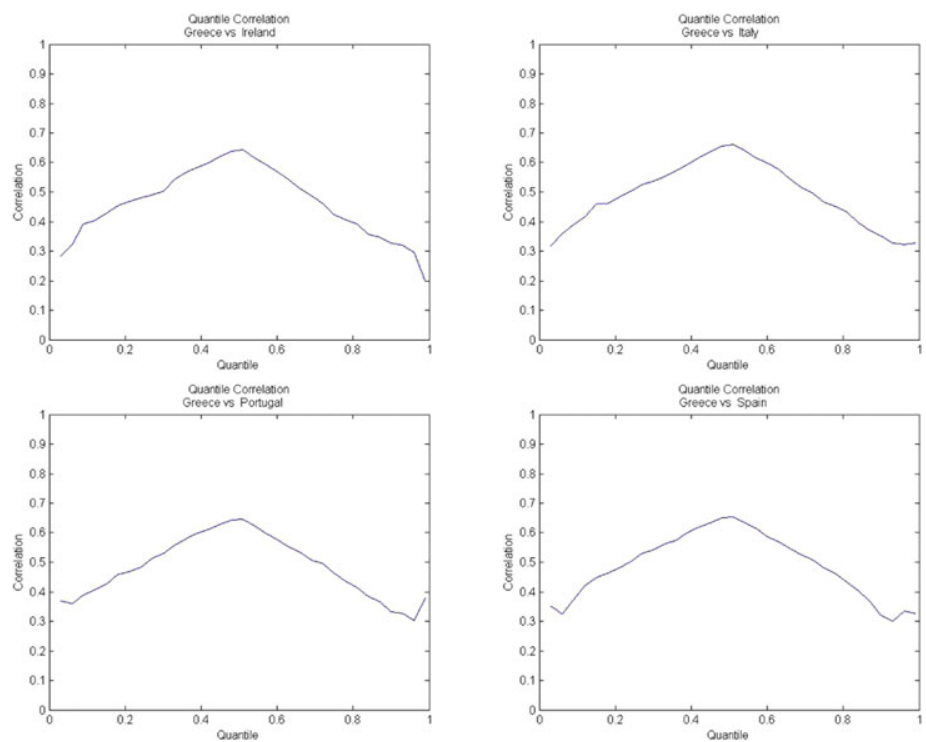

(B) Quantile dependence: Greece vs. advanced EU economies and Eurozone
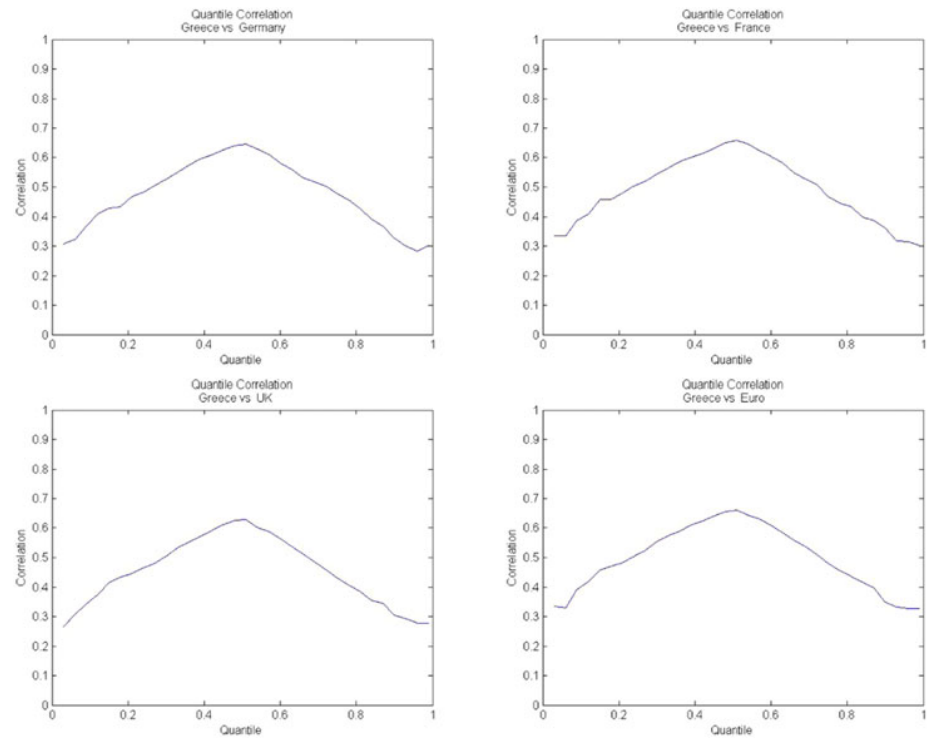

Figure 2

Quantile dependence: Greece versus PIIGS (Portugal, Ireland, Italy, Greece and Spain; Panel A), Greece versus advanced European Union (EU) economies and Eurozone (Panel B), and advanced EU economies and Eurozone versus each other (Panel C), January 1, 1999 to November 26, 2013 
(C) Quantile dependence: Advanced EU economies and Eurozone vs. each other
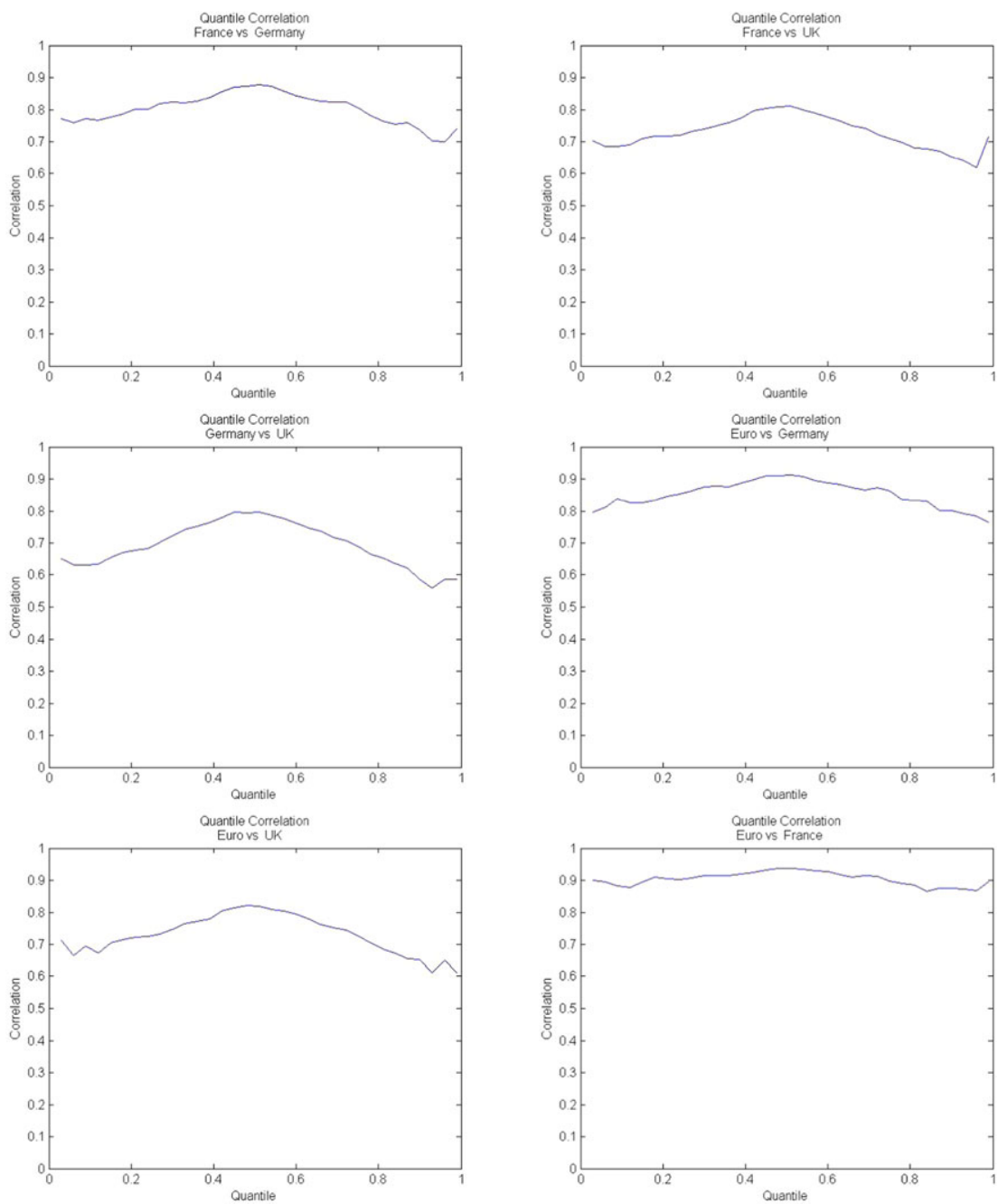

Figure 2

Continued.

Although quantile dependence graphs in Figure 2 pertaining to advanced Eurozone economies (e.g., Eurozone and France, France and Germany) show little change in correlation from one quantile to the next, quantile dependence among PIIGS economies as well as between PIIGS and advanced nations (e.g., Greece 
and Germany, Greece and Italy) reveals a sizeable change in correlation depending on which quantile is under consideration. In particular, the correlation is smaller at either high or low ends of the distribution relative to the middle quantiles. Thus, in the case of the PIIGS economies, we do not observe high extreme dependence between PIIGS and more stable European economies such as Germany, France and the UK. Our finding of high extreme dependence for the advanced countries and lower extreme dependence for the peripheral EU countries is similar to Christoffersen, Errunza, Jacobs and Langlois (2012), who report relatively large tail dependence for developed markets and relatively low tail dependence for emerging markets.

Our quantile dependence results also point to the near-symmetry when comparing high and low quantiles for each market. This finding is in agreement with Herrera and Eichler (2011), who use a copula-based nonparametric measure of extreme dependence to investigate the level and possible asymmetries in the extreme dependence for the European Monetary Union stock markets. Herrera and Eichler (2011) conclude that the degree of extreme dependence is high and that the dependence structure is largely symmetrical in the post-1999 period (the period studied in our paper), attributing this symmetry to the high degree of European integration and globalization. ${ }^{16}$

\subsection{Did comovements increase since the onset of the global financial crisis?}

Did the global financial crisis change the correlation structure across the PIIGS and the developed markets? Arguably, the degree of stock market comovements can change, especially as an economy transits from a relatively calm economic environment to a financial crisis. Two forms of changes can occur: first, correlations across pairs of countries can change, and second, the amount of correlation across different pairs of countries can change relative to one another.

To investigate the effect of the global financial crisis on the interdependence matrix across advanced and peripheral Eurozone countries, the UK, and the four non-EU nations, we split our sample into two periods. The first subsample starts on January 1, 1999, and runs through to June 30, 2007, and includes mostly tranquil periods in the stock markets and an expansionary phase of the business cycle. The second subsample starts with July 1, 2007, which many view as the starting date of the financial crisis, and runs through November 26, 2013, and thus spans much more turbulent periods, including the global financial crisis and the subsequent recovery. ${ }^{17}$

\footnotetext{
${ }^{16}$ Bekaert, Ehrmann, Fratzscher and Mehl (2014), however, do not find strong evidence in support of the "globalization hypothesis."

${ }^{17}$ July 2007 is sometimes referred to as "watershed" in the context of the events leading up to the collapse of Bear Stearns and, more broadly, to the global financial crisis (e.g., Maxfield, 2013). All of our results are robust to using January 2008 as the start of the global financial crisis. In addition, we end on November
} 
We calculate the three measures of association-Pearson coefficient, Spearman rho and Kendall's tau - for the first half and the second half of the sample. ${ }^{18}$ Similar to the results for the entire sample, we find that for each of the subsamples Pearson correlations are generally higher than Spearman's rho coefficients, which in turn are higher than Kendall's taus. We find that for all pairs of countries (except Japan), the realizations of Pearson, Spearman's rho and Kendall's tau correlation coefficients are higher for the second half of our sample (Table 5), and that these differences are statistically significant at the $1 \%$ level. ${ }^{19}$ The results in Table 5 suggest that EU cross-country pairwise correlations increased over $10 \%$ (France-Germany) to $16 \%$ (UK-Germany) for developed nations and between 15\% (Ireland-Greece) and 30\% (Portugal-Italy) for the PIIGS countries. Notably, Portugal's correlations increased across the board. Besides Portugal's cross-correlations, the general increase is about $12 \%$ (Italy-Spain) to $23 \%$ (Greece-Italy) and the increases are similar in magnitude between the PIIGS to advanced economies before and after the global financial crisis. In general, the increases were relatively similar.

Also of interest are the UK's changes relative to the Eurozone and the non-EU countries. For the most part, the changes across the periods for the UK mirror those of the Eurozone nations as shown in the first half of Table 5. The changes across the two periods for the UK and the non-EU countries shown in the second half of Table 5 also are interesting. Again, the increases in comovement among the UK and other countries tend to be similar to those for Switzerland, and the increases in comovement are larger for the UK than for Switzerland (for France and the Eurozone, the Pearson coefficient is smaller, but the Spearman's rho and Kendall's taus are both larger). Given that the UK's comovements with France and Germany were already higher than Switzerland's in the first half, the larger increase in comovements is particularly indicative as there was less room to rise.

Overall, the results are indicative of the more pronounced comovements during the global financial crisis. This is consistent with Longin and Solnik (2001), who report higher comovements in bear markets among MSCI equity indices for a sample ending in 1996. The increased comovements that we observe in our sample are also in line with an upward trend in return correlations for the European stock markets reported by Bekaert, Hodrick and Zhang (2009). The values of our three

26, 2013, to include Greece. All of the results are consistent if we exclude Greece and extend the sample through September 2015.

${ }^{18}$ The resulting tables are not reported here to conserve space but are available from the authors on request.

${ }^{19}$ To determine whether any two correlations are significantly different from each another, we implement a test of equivalence of correlation coefficients, $H_{0}: r_{1}=r_{2}$. If Fisher's $z$-transform (see, e.g., Papoulis, 1990) is applied to both correlations: $z_{i}=\frac{1}{2} \ln \left(\frac{1+r_{i}}{1-r_{i}}\right), i=1,2$, then $\frac{z_{1}-z_{2}}{\sqrt{\frac{1}{N_{1}-3}+\frac{1}{N_{2}-3}}} \stackrel{a}{\sim} N(0,1)$, where $N_{1}$ and $N_{2}$ are sample sizes. For example, given our subsamples $\left(N_{1}=2,215\right.$ and $\left.N_{2}=1,672\right)$, a change in correlation from 0.5 to 0.56 would be significant at $1 \%$. Also significant at $1 \%$ would be a change from 0.9 to 0.915 . 


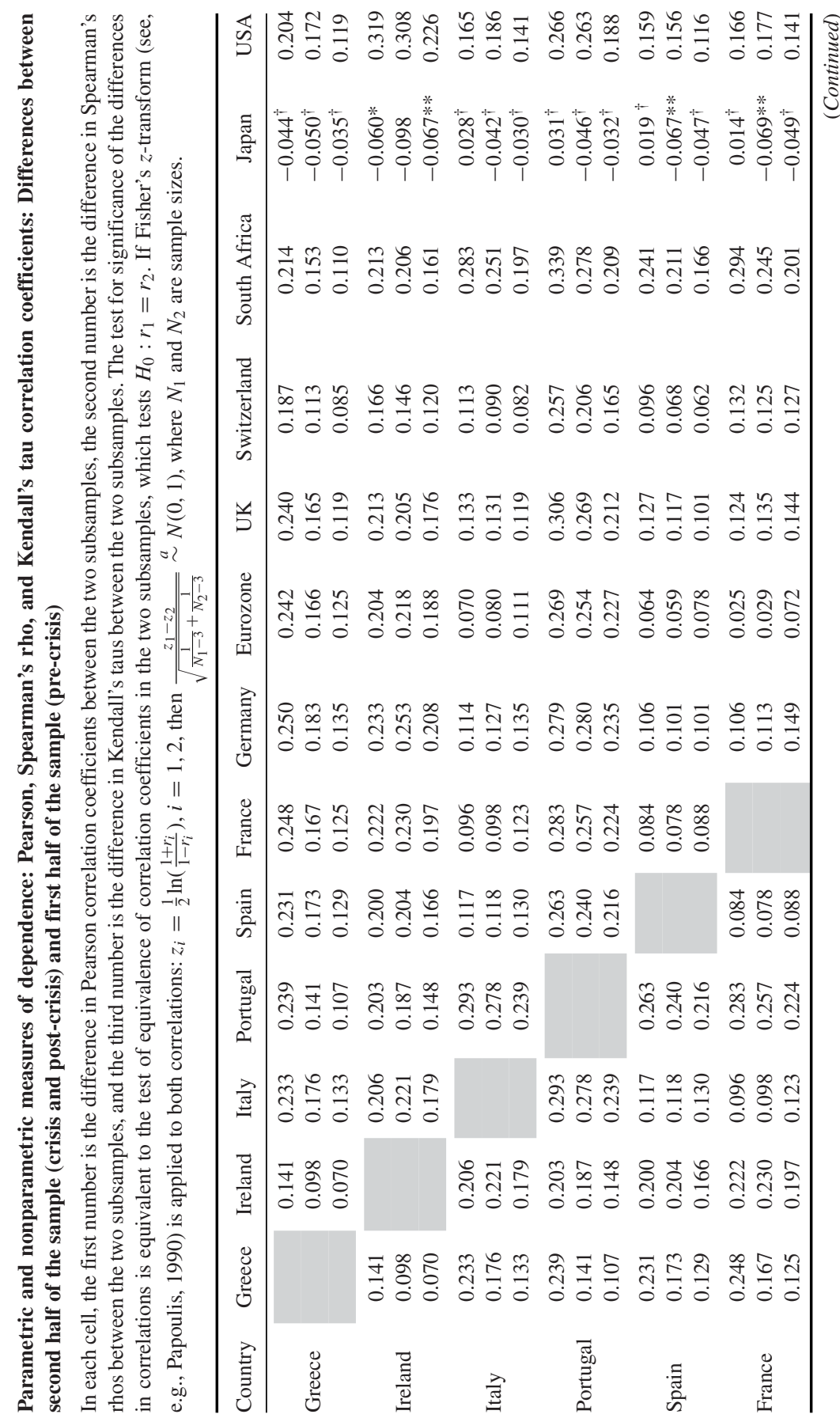




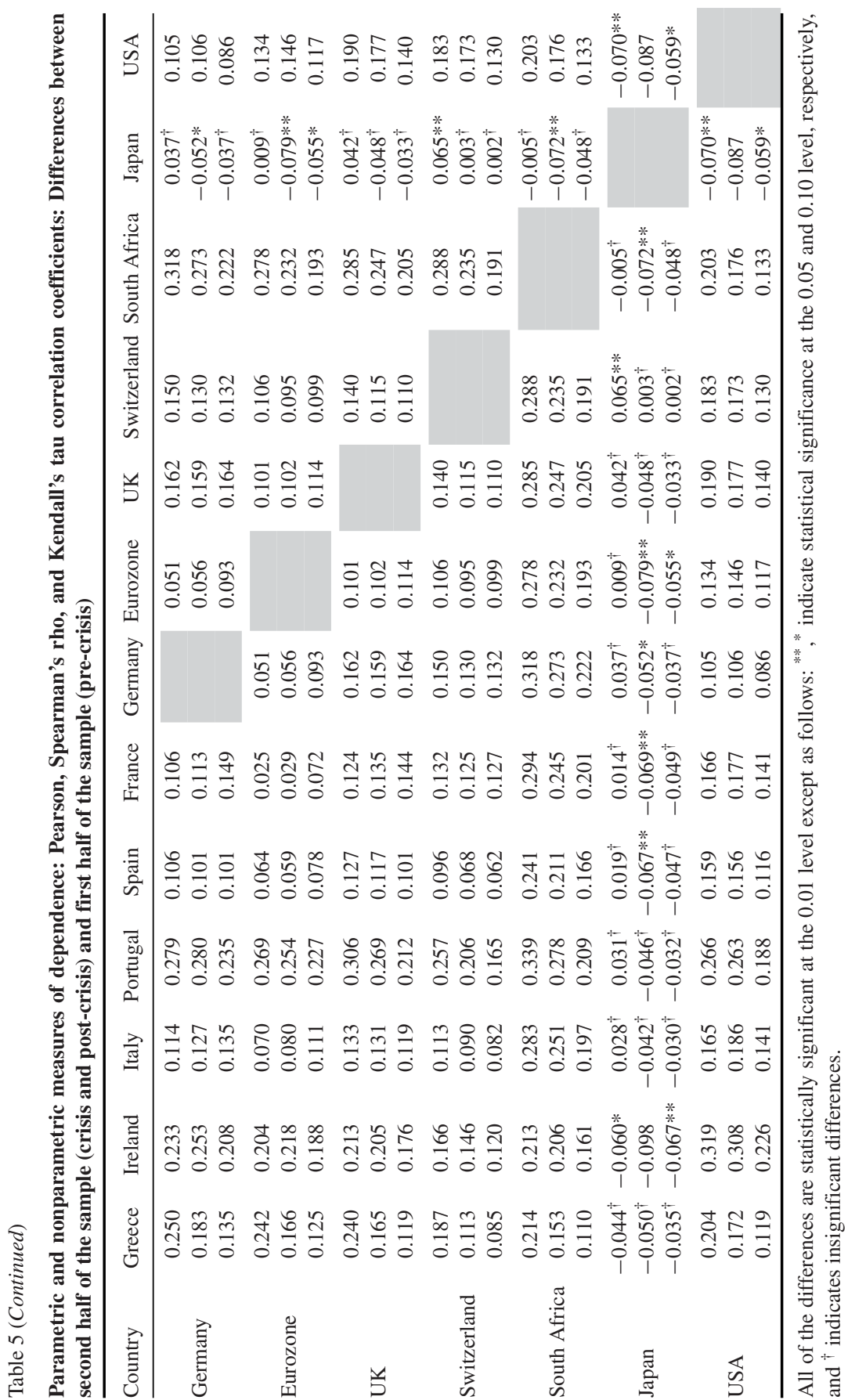


measures of association are lower for the first half of the sample relative to the overall sample (and relative to the second half). This result can be accounted for by the much lower volatility — and therefore covolatility — of returns prior to 2007 . So, it is true that interdependence increased after the global financial crisis. This result supports the findings of Forbes and Rigobon (2002) and Rodriguez (2007) of increased interdependence during earlier crises, such as the Mexican crisis of 1994 and the Asian crisis of 1997.

This increase after the global financial crisis is not the end of the story, however. We observe that while all linear and nonlinear measures of dependence are higher during the second half of the sample, the same pattern of relationship holds in each subsample as in the entire sample. Namely, pairwise correlations are lowest on average across PIIGS with each other, correlations between the PIIGS and the developed EU nations (France, Germany, and the UK) are higher, and correlations among the developed countries are the highest. For example, focusing on the Spearman's rho correlation coefficients, in the first half of the sample, the average of correlations among PIIGS was 0.47, the average of correlations between PIIGS and developed EU economies was 0.57, and the average of correlations among the developed EU countries was 0.76 . In the second half of the sample, the average correlations were 0.66 among PIIGS, 0.75 for PIIGS versus developed EU economies, and 0.90 for the developed EU nations. ${ }^{20}$

Thus, while there was an increase in comovement from the pre-crisis to crisis periods, our main results with regard to the ordering of correlations hold in both tranquil and turbulent periods. So, while we find that correlations increased, the relative correlation structure across these markets did not change with the onset of the global financial crisis. This is consistent with the Eurozone countries being sensitive to a common economic factor, whose importance increased with the onset of the recent financial crisis. For example, European financial markets may now be more dependent on the forward guidance and interest rate policies adopted by the ECB and the Bank of England. As emphasized in Stubbington, Zeng and Wei (2015, para. 4), "[t]he bouts of turmoil highlight markets' growing reliance on the words and actions of central banks in the years following the financial crisis." Our results for the four non-EU countries (Switzerland, the United States, Japan, and South Africa) support this conclusion and highlight the similarities between Switzerland and the UK, while still indicating higher comovements for the UK with the other EU nations.

Figure 3 further illustrates this point by plotting the changes in Pearson correlations between pre- and post-2007 periods for several pairs of countries. We observe

\footnotetext{
${ }^{20}$ Although generally consistent across countries, Table 5 does note some interesting differences. The correlations for Ireland, Greece, and Portugal generally increased by about 0.2 to 0.3 from the pre-crisis period to the crisis period, while Spain, Italy, France, the UK and Germany tended to increase between 0.1 and 0.2 . Part of the limitation of the increase might be structural. In the former period, correlations for France, Germany and the UK were already above 0.7 ; in the latter period, the correlations among these countries were around 0.9 . (The theoretical limit of 1.0 for correlations curbed notable further increases.)
} 


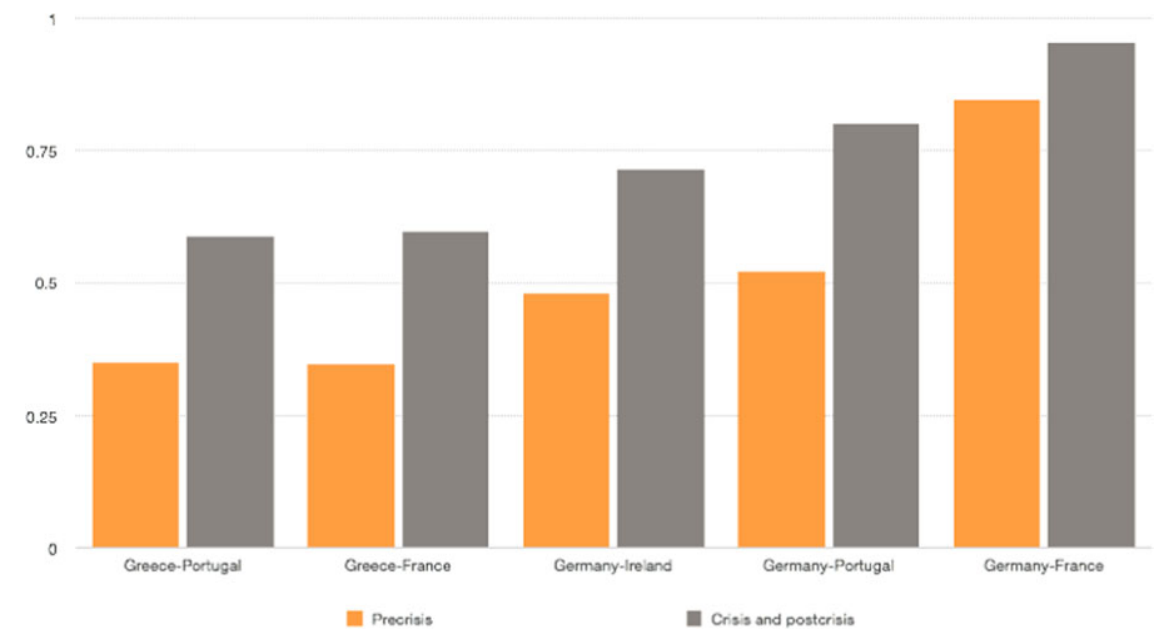

Figure 3

Changes in correlations between the first half of the sample (January 1, 1999 to June 30, 2007) and the second half of the sample (July 1, 2007 to November 26, 2013)

that the correlations have increased but that this increase is generally uniform (with the exception of the phenomenon outlined in footnote 20). Although international equity markets are expected to be more correlated during bear markets (e.g., Ang and Bekaert, 2002), our findings that, for example, the France-Germany comovements are greater than the Greece-Ireland comovements during the crisis (in addition to the tranquil period) are both surprising and interesting. They suggest that during turbulent times, the advanced economies should be more concerned about market volatility in other advanced nations than in the economies that are historically more prone to financial instability such as PIIGS.

These findings are confirmed when we compare scatterplot matrices for the two subsamples. ${ }^{21}$ Correspondence between any pair of countries' returns is closer (as evidenced by a tighter fit around the $45^{\circ}$ line) —and, therefore, comovements are more pronounced-for the second half of the sample that includes the global financial crisis. Thus, the values of the measures of associations are higher during the subsample that includes the financial crisis. This is in line with much of the literature that suggests that comovements must be more pronounced during crises (e.g., Bekaert, Harvey and $\mathrm{Ng}, 2005$ ). Even so, the relative ordering holds. Even during the crisis period, the advanced EU markets were more interdependent with each other than the PIIGS were with each other, or even than the PIIGS were with

${ }^{21}$ Due to space considerations, the figures are not reported but are available on request. 
the advanced EU markets, and the UK comoved more with the EU than does non-EU Switzerland.

Our results pertaining to the comparison of market comovements in pre-crisis and turbulent periods can also be construed as an indirect empirical test of Kodres and Pritsker's (2002) theoretical study. ${ }^{22}$ Our results are largely consistent with the broad implications of the model (e.g., that a financial contagion can occur among countries that do not share the same macroeconomic fundamentals). However, we also report empirical findings that may differ from possible implications in Kodres and Pritsker (2002): for example, our finding that all comovements increased by about the same amount does not in this case necessarily imply that less advanced economies are more vulnerable to contagion, or that lower information asymmetry is guaranteed to reduce a country's vulnerability to contagion. ${ }^{23}$

\subsection{Did the comovements change between crisis and recovery?}

One may wonder if the results reported above may be an artifact of combining the crisis and recovery periods into one subsample. Here, we further refine our results by studying the global financial crisis and recovery periods separately and comparing market comovements between the two periods and with the pre-crisis period. To this end, we define the global financial crisis as starting in July 2007 (consistent with our previous analysis) and ending in June 2009. One way in which our study of comovements relates to the literature on contagion is that the period of financial crisis is institutionally determined, as most agree that the recent crisis started in mid 2007 and ended (approximately) by mid 2009. ${ }^{24}$ These dates are consistent with the data on the main macroeconomic and financial indicators such as GDP and stock market indices. For example, Italy had negative GDP growth in 2007:Q3 and 2007:Q4, while the big European economies began to shrink in 2008:Q2. The euro area shows positive GDP growth starting with 2009:Q3. ${ }^{25}$ Further, the literature defines a stock market crisis as a sharp fall in the stock market index (Pericoli and Sbracia, 2003). According to this definition, the stock market crisis in Europe ended by mid 2009. Thus, the macroeconomic indicators suggest that the financial crisis in Europe (which

\footnotetext{
22 Three specific channels of contagion can be studied in the context of Kodres and Pritsker's (2002) model: correlated information (e.g., King and Wadhwani, 1990), correlated liquidity shock (e.g., Yuan, 2005), and cross-market rebalancing (e.g., Kodres and Pritsker, 2002).

${ }^{23}$ Kodres and Pritsker (2002) argue that relatively less developed countries are characterized by relatively higher information asymmetries; however, we do not find, for example, that Greece is more susceptible to contagion than Germany.

${ }^{24}$ Such an approach of using institutional information to establish the cut-off dates of a crisis helps alleviate endogeneity concerns. The next subsection conducts a robustness check by identifying crisis events using a measure of extreme negative comovements.

${ }^{25}$ See the Organisation for Economic Co-operation and Development (OECD) statistics, http://stats.oecd. org/Index.aspx?QueryName=350\&QueryType $=$ View \&Lang $=$ en
} 
Table 6

Comovements among PIIGS (Portugal, Ireland, Italy, Greece and Spain), advanced European Union (EU), and non-EU countries during pre-crisis (January 1, 1999 to June 30, 2007), crisis (July 1, 2007 to June 30, 2009), and recovery (July 1, 2009 to November 26, 2013) periods: Average of Pearson correlation coefficients

The last two columns of the table show the difference between the crisis and pre-crisis periods and the difference between the recovery and crisis periods. The significance tests are $t$-tests for the difference in means, except for UK-Switzerland, which is done in both cases using Fisher's $z$-transform-based test as in Table 5.

\begin{tabular}{lccccc}
\hline Groups of countries & Pre-crisis & Crisis & Post-crisis & $\begin{array}{c}\text { Crisis minus } \\
\text { pre-crisis }\end{array}$ & $\begin{array}{c}\text { Post-crisis } \\
\text { minus crisis }\end{array}$ \\
\hline $\begin{array}{l}\text { PIIGS with PIIGS } \\
\text { Advanced EU with } \\
\quad \text { PIIGS }\end{array}$ & 0.472 & 0.689 & 0.645 & $0.217^{* * *}$ & -0.044 \\
$\begin{array}{l}\text { Advanced EU with } \\
\quad \text { advanced EU }\end{array}$ & 0.824 & 0.791 & 0.748 & $0.204^{* * *}$ & -0.043 \\
$\begin{array}{l}\text { Non-EU with PIIGS } \\
\text { Non-EU with }\end{array}$ & 0.343 & 0.547 & 0.486 & $0.204^{* * *}$ & -0.061 \\
$\quad \begin{array}{l}\text { advanced EU } \\
\text { Non-EU with non-EU }\end{array}$ & 0.454 & 0.610 & 0.607 & $0.156^{*}$ & -0.003 \\
$\quad$ UK with Switzerland & 0.254 & 0.359 & 0.378 & 0.105 & 0.019 \\
\hline
\end{tabular}

$* * * * * * *$ indicate statistical significance at the $0.01,0.05$ and 0.10 level, respectively.

is not necessarily synonymous with the European debt crisis) was over by the end of $2009 .{ }^{26}$

Table 6 and Figure 4 summarize our main findings by reporting comovements among PIIGS, between PIIGS and advanced EU countries, and among advanced EU economies, as measured by average Pearson correlations, for all relevant pairs of countries, as well as the non-EU countries with these groups and with themselves (non-EU with non-EU). ${ }^{27}$ As the UK and Switzerland are of particular interest, we also separate out the UK's comovement with Switzerland. In line with our previous results, we find that comovements within and across the groups of countries were higher following the onset of the global financial crisis and interestingly were of approximately the same magnitude for comparable groups. For example, comovements of advanced EU countries with PIIGS increased by 0.204 from the pre-crisis to the crisis period, as did the comovements of non-EU countries with PIIGS; the increase

\footnotetext{
${ }^{26}$ To check if our results are robust to alternative cut-off dates for the global financial crisis, we use January 2008 to December 2009 as the alternative definition of the crisis and compare the two sets of results for the three comovement metrics (Pearson correlation, Spearman's rho and Kendall's tau) for the four subsamples-pre-crisis, crisis and post-crisis combined, crisis, and recovery. The greatest relative difference across all metrics and all subsamples is $8.2 \%$, with the majority of differences being less than $2 \%$. Thus, all of the results reported in this paper are robust to using 2008-2009 as the crisis period.

27 The results for Spearman's rho and Kendall's tau coefficients are similar.
} 


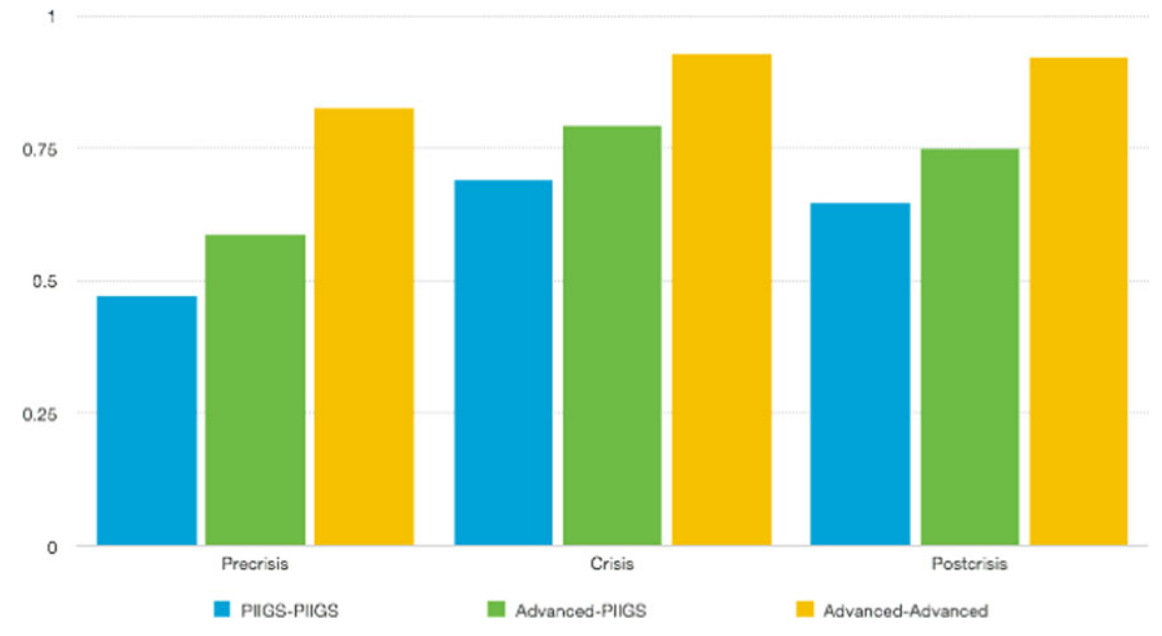

Figure 4

Comovements among PIIGS (Portugal, Ireland, Italy, Greece and Spain), between PIIGS and advanced economies, and among advanced economies during pre-crisis (January 1, 1999 to June 30, 2007), crisis (July 1, 2007 to June 30, 2009), and recovery (July 1, 2009 to November 26, 2013) periods: Average correlations

for advanced EU with each other was 0.104, and the increase for the non-EU with each other was almost the same at 0.105 . Additionally, the comovements among the more advanced countries were higher than among PIIGS and higher than between PIIGS and advanced countries in all three periods-before, during, and after the global financial crisis. The increases in comovements from pre-crisis to crisis periods were all significant (with the exception of comovements of non-EU countries with each other).

Most striking in this new set of results is the finding that the level of comovements barely changed between the crisis and recovery periods. For instance, the first row of Table 6 shows that the average correlation among the PIIGS countries was 0.47 prior to the global financial crisis, went up notably to 0.69 during the recession, and then barely decreased to 0.65 during the recovery phase. The evolution of the average correlation between PIIGS and advanced economies was similar in relative terms, albeit at a higher level: 0.59 during the pre-crisis period, 0.79 during the crisis, and 0.75 after the global financial crisis. The average correlation among the advanced economies was higher than among PIIGS or between PIIGS and advanced nations during all periods: it went up from 0.82 to 0.93 with the onset of the global financial crisis and stayed nearly constant (went down by only 0.006) as Europe began to recover. Similar results were found for the non-EU countries. As evident from the last column of Table 6 , all differences in the average correlations between crisis and 
post-crisis periods are economically de minimis and in fact increased among the non-EU countries by a small amount. Even the non-EU comovements with the advanced EU countries increased by about 0.16 during the crisis and were mitigated by only a negligible amount $(-0.003)$ post-crisis. The comovements during the recovery are statistically indistinguishable from those during the crisis.

Thus, our results show that not only did the relative comovement structure remain the same across our entire post-1999 sample but also the actual (absolute) structure was virtually constant between the crisis and post-crisis periods. This is an important result, as it indicates that the level of stock market comovements was permanently affected by the global financial crisis.

\subsection{Extreme comovements}

Thus far, we examined the entire range of returns observed in our sample starting with the introduction of the euro, as well as in three subsamples including the crisis period. The empirical literature frequently associates financial crisis with extreme negative comovements (e.g., Rodriguez, 2007). To check how our results based on the institutional definition of a crisis compare with what one may observe using this alternative definition, we compute copula-based lower tail dependence coefficients for each of the 36 pairs of EU stock markets (including the UK). As outlined in Section 2, this measure of extreme negative comovements is defined as the limit of conditional probability that the realization of one country's return is less than a certain percentile, given that another country's return is also less than the same percentile (upper tail dependence is defined similarly). In other words, we now explore comovements between each pair of stock markets when market returns take on extreme negative values. ${ }^{28}$

Table 7 presents the coefficients of lower and upper tail dependence at the $5 \%$ quantile (i.e., bottom $5 \%$ and top 5\%). The results corroborate our findings reported in the preceding subsections. In particular, the average of extreme negative comovements is 0.459 among the PIIGS, 0.532 between the PIIGS and the advanced EU countries, and 0.689 among the advanced EU nations. The results for the $1 \%$ cutoff are similar. ${ }^{29}$ Thus, our previous findings - namely, that the comovements among the advanced markets are greater than between the PIIGS and the advanced nations, which in turn are greater than the comovements among the PIIGS-hold even if we

\footnotetext{
${ }^{28}$ Asymptotic dependence requires large samples to be estimated accurately, and we believe that our time series dimension with 3,887 daily observations is sufficient in this regard. Another potential issue may stem from the bias-efficiency tradeoff in estimating asymptotic dependence: having a larger sample for the tail quantile will yield more efficient tail estimates but may lead to a bias (e.g., Poon, Rockinger and Tawn, 2004; de Haan and Ferreira, 2006, Chapter 3). Our quantile dependence results (Fig. 2) point to the stability of the point estimates for various quantiles, which suggests that our relatively large sample size does not lead to a significant bias.

${ }^{29}$ The results for the $1 \%$ lower and upper tails are not reported here but are available on request.
} 


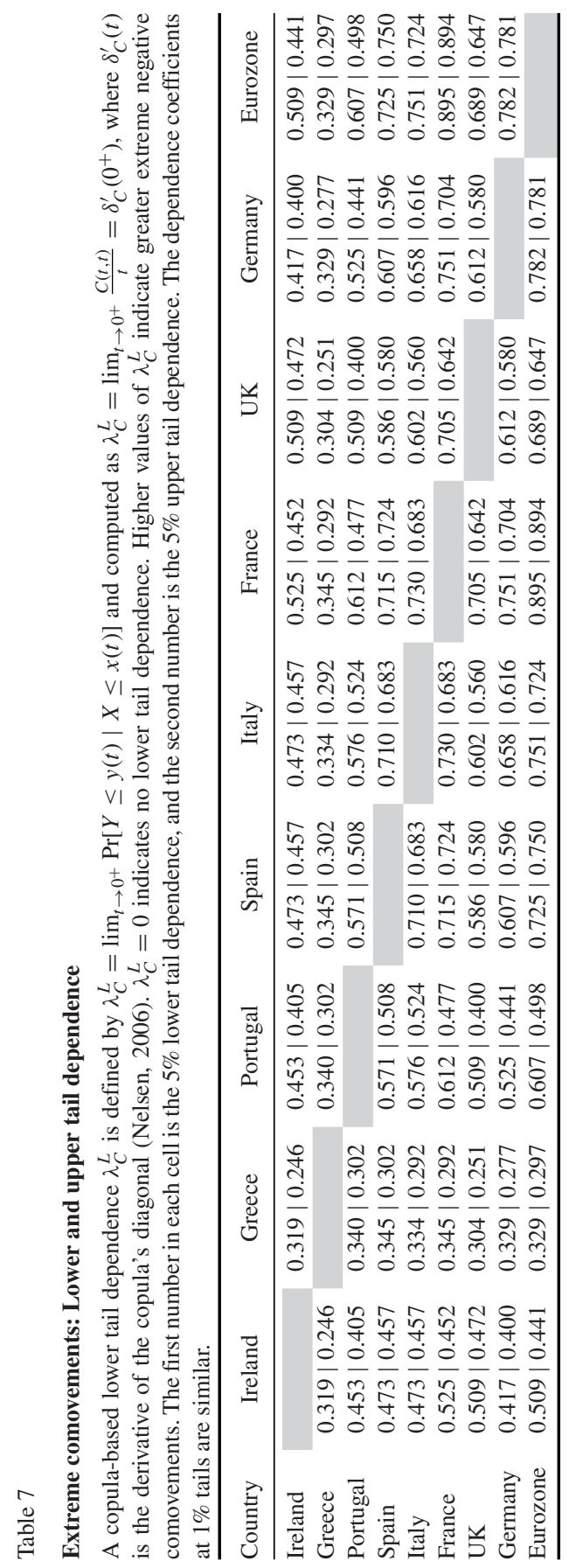


define crisis by way of extreme negative comovements. The upper tail dependence coefficients are slightly different from the lower tail dependence numbers, which points to the mild tail asymmetry and suggests that advanced nations show stronger comovements with one another than with the peripheral EU economies during bullish markets as well, consistent with Herrera and Eichler (2011).

\section{Can macroeconomic or market factors account for the comovements?}

We now turn to the effects on the pattern of comovements of variation in macroeconomic and market factors, such as ECB monetary policy, market interest rates, risk and uncertainty (as proxied by VIX), euro-dollar exchange rate, as well as FamaFrench risk factors and U.S. and global market factors. Controlling for these various factors connects our results to both the financial contagion literature and the financial comovements research. Our methodology in this section is similar to Boyson, Stahel and Stulz (2010) and Bekaert, Ehrmann, Fratzscher and Mehl (2014), and follows closely the literature's consensus definition of contagion in Bekaert, Harvey and $\mathrm{Ng}$ (2005) - namely, that contagion is an increase in comovements relative to what would have been expected based on the changes in the economic fundamentals.

\subsection{Monetary policy}

We begin our robustness analysis by exploring the possibility that the comovements before, during, and after the financial crisis may have been driven by the changes in the ECB's monetary policy. To control for the monetary policy, we orthogonalize each country's stock market returns by the ECB marginal rate and then use the residuals from the following regressions: $R_{i, t}=\beta_{0}+\beta_{1} \cdot$ ECBrate $_{t}+\epsilon_{t}$, where $R_{i, t}$ is country $i$ 's stock market return and ECBrate $_{t}$ is the ECB marginal lending rate, to calculate the parametric and nonparametric measures of dependence (i.e., Pearson, Spearman's rho and Kendall's tau coefficients). The resulting cross-country correlations (not reported here for brevity but available on request) are virtually identical to the ones reported for the raw data in Table 3. In particular, the change in all three measures of dependence for all but one pair of countries is less than $1 \%$. The only exception is the United States-Japan correlations, which changed by about $5 \%$.

These results carry over to the average comovements among and within the three groups of countries-PIIGS, advanced EU and non-EU. Table 8 reports the comovements, as measured by average Pearson correlations, before, during, and after the global financial crisis; the results for Spearman's rho and Kendall's tau coefficients are similar. The last two columns show the difference between the crisis and pre-crisis periods and the difference between the recovery and crisis periods. The significance tests are $t$-tests for the difference in means, except for UK-Switzerland, which is done using Fisher's $z$-transform-based test as in Table 5. A comparison of Table 8 
Table 8

Controlling for the European Central Bank's (ECB) monetary policy (ECB marginal lending rate): Comovements among PIIGS, advanced European Union (EU) and non-EU countries during precrisis (January 1, 1999 to June 30, 2007), crisis (July 1, 2007 to June 30, 2009), and recovery (July 1, 2009 to November 26, 2013) periods: Average correlations

This table explores the possibility that the European monetary policy may explain the observed pattern of comovements. To control for the monetary policy, each country's stock market returns are orthogonalized by the ECB's marginal lending rate. The table reports group averages of cross-country correlations of the residuals from the following regressions: $R_{i, t}=\beta_{0}+\beta_{1} \cdot$ ECBrate $_{t}+\epsilon_{t}$, where $R_{i, t}$ is country $i$ 's stock market return and ECBrate $_{t}$ is the ECB marginal lending rate. The last two columns show the difference between the crisis and pre-crisis periods and the difference between the recovery and crisis periods. The significance tests are $t$-tests for the difference in means, except for UK-Switzerland, which is done in both cases using Fisher's z-transform-based test as in Table 5.

\begin{tabular}{lccccc}
\hline Groups of countries & Pre-crisis & Crisis & Post-crisis & $\begin{array}{c}\text { Crisis minus } \\
\text { pre-crisis }\end{array}$ & $\begin{array}{c}\text { Post-crisis } \\
\text { minus crisis }\end{array}$ \\
\hline $\begin{array}{l}\text { PIIGS with PIIGS } \\
\text { Advanced EU with }\end{array}$ & 0.478 & 0.749 & 0.673 & $0.270^{* * *}$ & -0.075 \\
$\quad$ PIIGS & 0.597 & 0.825 & 0.775 & $0.228^{* * *}$ & -0.050 \\
$\begin{array}{l}\text { Advanced EU with } \\
\quad \text { Advanced EU }\end{array}$ & 0.841 & 0.942 & 0.938 & $0.101^{* *}$ & -0.004 \\
$\begin{array}{l}\text { Non-EU with PIIGS } \\
\text { Non-EU with }\end{array}$ & 0.342 & 0.546 & 0.485 & $0.205^{* * *}$ & -0.061 \\
$\quad$ Advanced EU & 0.453 & 0.610 & 0.606 & $0.157^{*}$ & -0.003 \\
$\quad \begin{array}{l}\text { Non-EU with non-EU } \\
\text { UK with Switzerland }\end{array}$ & 0.253 & 0.358 & 0.378 & 0.105 & 0.020 \\
\hline
\end{tabular}

$* * *, * * *$ indicate statistical significance at the $0.01,0.05$ and 0.10 level, respectively.

with Table 6 reveals that the structure of comovements across pre-crisis, crisis, and post-crisis periods is immune to controlling for the ECB policy: namely, that the comovements increased significantly during the global financial crisis and remained at this higher level during the post-crisis period. In fact, each of the summary averages by group pairs change by less than $1 \%$ relative to the group averages reported for the raw returns in Table 6. Also intact are the cross-sectional differences: for all subperiods, the comovements among advanced EU countries are more pronounced than the comovements of advanced EU economies with PIIGS, which in turn are greater than the comovements within the PIIGS group. We conclude, therefore, that the ECB policy is not the common factor that can explain the structure of stock market comovements.

\subsection{Market factors}

Next, we examine whether the observed structure of comovements, either among the various groups of countries or across time, is influenced by other macroeconomic and market factors. To this end, we control for the following factors available at daily 
frequency: euro LIBOR three-month rate, Chicago Board Options Exchange (CBOE) VIX, and the euro-dollar exchange rate. ${ }^{30}$ Table 9 reports cross-country correlations of the residuals from the following regressions: $R_{i, t}=\beta_{0}+\beta_{1} \cdot$ LIBOR $_{t}+\beta_{2} \cdot V I X_{t}+$ $\beta_{3} \cdot$ ExchRate $_{t}+\epsilon_{t}$, where $R_{i, t}$ is country $i$ 's stock market return, LIBOR is $_{t}$ the euro LIBOR three-month rate, VIX ${ }_{t}$ is the CBOE VIX, and ExchRate E $_{t}$ is the eurodollar exchange rate. In each cell, the first number is Pearson correlation coefficient, the second number is Spearman's rho, and the third number is Kendall's tau. All coefficients are significant at the $1 \%$ level except for the United States-Japan pair.

As expected, most of the correlation coefficients are reduced as a result of orthogonalizing the stock market returns by these three factors. Even so, all of the measures of dependence for all pairs of countries (with the exception of the United States-Japan pair) changed by no more than $5 \%$, as compared with the raw return correlations (Table 3). This relative similarity suggests that the comovements structure across time and across groups of countries should be largely preserved in the face of controlling for the LIBOR rate, VIX and the exchange rate. Table 10 confirms this by showing the average orthogonalized comovements among PIIGS, advanced EU and non-EU economies before, during, and after the financial crisis. As compared with the correlations in raw returns (Table 6), controlling for the market factors reduces each of the group averages by only $3 \%$ or less. Similar to the raw returns results, we find that the comovements for all combinations of groups of countries (except for non-EU countries with each other) increase significantly during the global financial crisis and that there was no significant reduction in level of these comovements after the crisis had ended.

\subsection{Fama-French factors}

We next control for Fama-French risk factors that could be driving the results. Accordingly, we orthogonalize each country's stock market returns using the daily Fama-French equity market factors. ${ }^{31}$ We compute cross-country correlations of the residuals from the Fama-French three-factor model with market portfolio return, market capitalization (SMB [small minus big]) and book-to-market (HML [high minus low]) factors. ${ }^{32}$ The results, which are omitted due to space considerations but are available on request, show that with the exception of U.S. comovements with

\footnotetext{
${ }^{30}$ Bekaert, Ehrmann, Fratzscher and Mehl (2014), for example, use VIX as a proxy for risk aversion and emphasize the importance of considering the interest rate and exchange rate exposures.

${ }^{31}$ The daily factors are available from Kenneth French's Web site (http://mba.tuck.dartmouth. edu/pages/faculty/ken.french/data_library.html).

${ }^{32}$ Although substantial progress has been made by other countries, the United States is widely believed to be the world financial leader, particularly before, during, and after the crisis period. For consistency, we use daily U.S. Fama-French factors.
} 


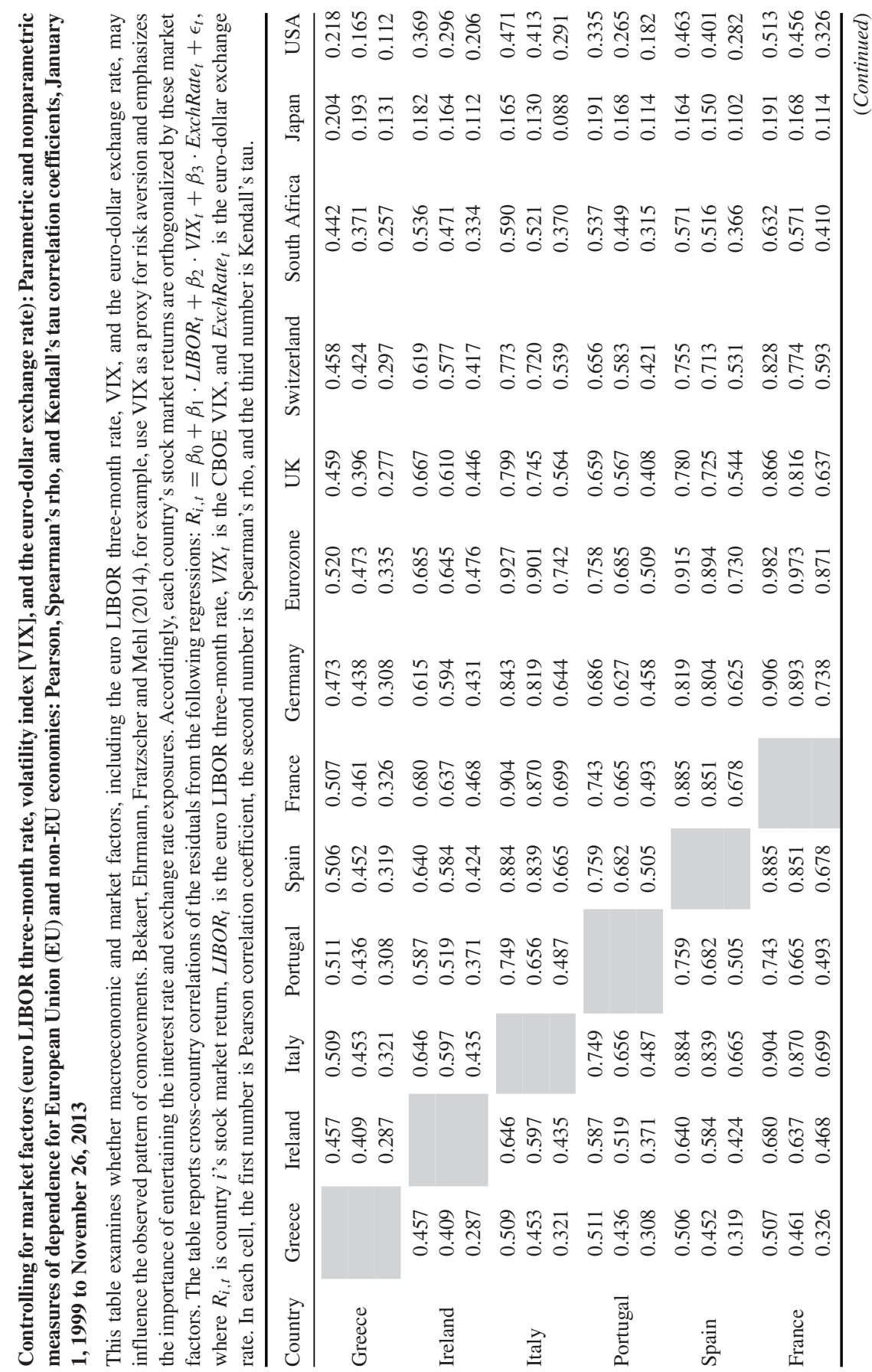




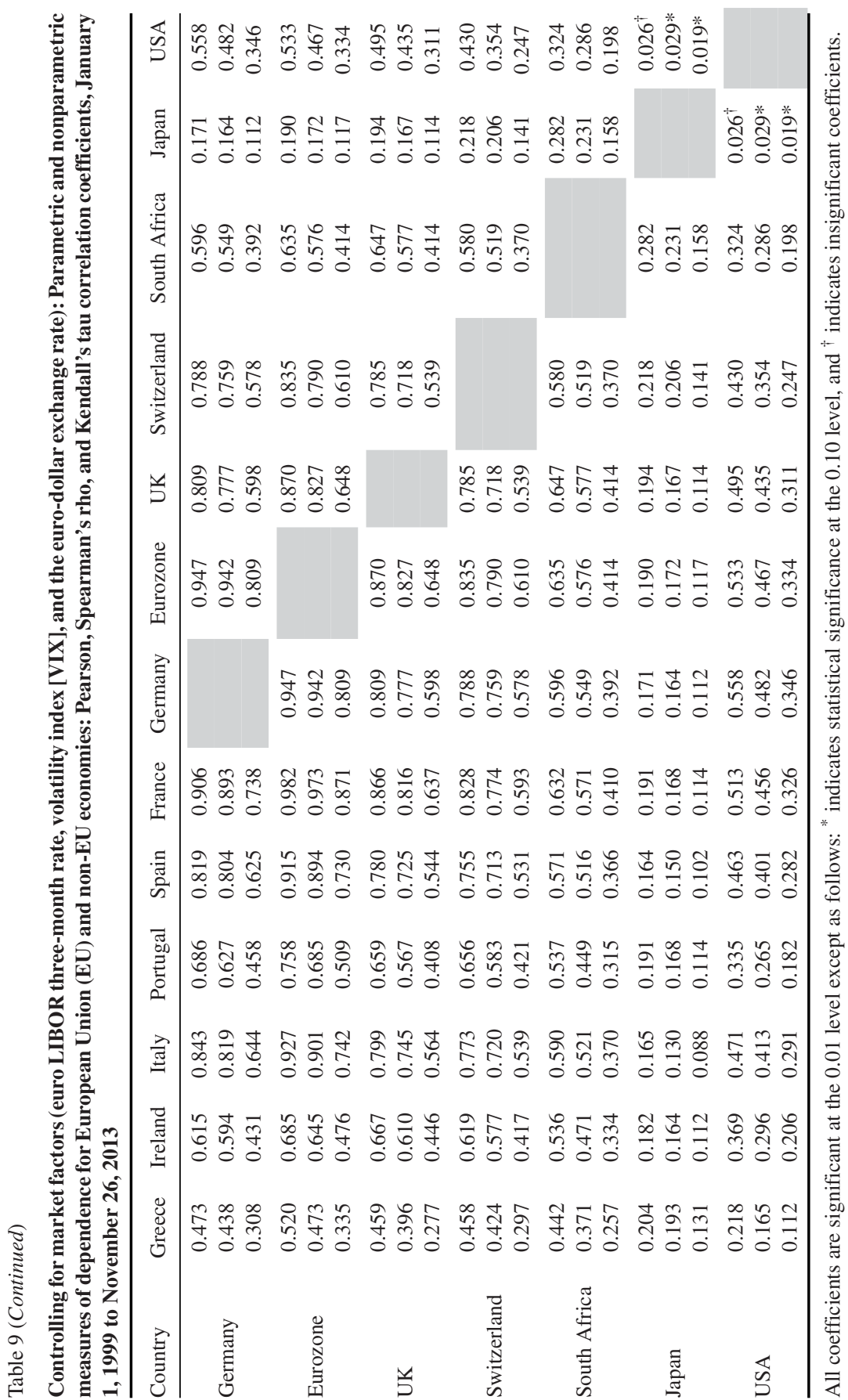


Table 10

Controlling for market actors (euro LIBOR three-month rate, volatility index [VIX], and euro-dollar exchange rate): Comovements among PIIGS (Portugal, Ireland, Italy, Greece and Spain), advanced European Union (EU), and non-EU countries during pre-crisis (January 1, 1999 to June 30, 2007), crisis (July 1, 2007 to June 30, 2009), and recovery (July 1, 2009 to November 26, 2013) periods: Average correlations

This table examines whether macroeconomic and market factors, including the euro LIBOR three-month rate, VIX, and the euro-dollar exchange rate, may explain the observed pattern of comovements. Bekaert, Ehrmann, Fratzscher and Mehl (2014), for example, use VIX as a proxy for risk aversion and emphasizes the importance of entertaining the interest rate and exchange rate exposures. Accordingly, each country's stock market returns are orthogonalized by these market factors. The table reports group averages of cross-country correlations of the residuals from the following regressions: $R_{i, t}=\beta_{0}+\beta_{1} \cdot$ LIBOR $_{t}+$ $\beta_{2} \cdot$ VIX $_{t}+\beta_{3} \cdot$ ExchRate $_{t}+\epsilon_{t}$, where $R_{i, t}$ is country $i$ 's stock market return, LIBOR $_{t}$ is the euro LIBOR

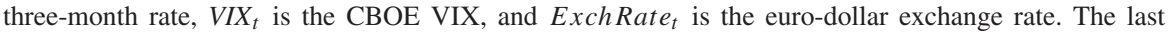
two columns show the difference between the crisis and pre-crisis periods and the difference between the recovery and crisis periods. The significance tests are $t$-tests for the difference in means, except for UK-Switzerland, which is done in both cases using Fisher's z-transform-based test as in Table 5.

\begin{tabular}{lccccc}
\hline Groups of countries & Pre-crisis & Crisis & Post-crisis & $\begin{array}{c}\text { Crisis minus } \\
\text { pre-crisis }\end{array}$ & $\begin{array}{c}\text { Post-crisis } \\
\text { minus crisis }\end{array}$ \\
\hline $\begin{array}{l}\text { PIIGS with PIIGS } \\
\text { Advanced EU with }\end{array}$ & 0.474 & 0.745 & 0.670 & $0.271^{* * *}$ & -0.075 \\
$\quad$ PIIGS & 0.593 & 0.822 & 0.772 & $0.230^{* * *}$ & -0.050 \\
$\begin{array}{l}\text { Advanced EU with } \\
\quad \text { advanced EU }\end{array}$ & 0.839 & 0.941 & 0.937 & $0.102^{* *}$ & -0.003 \\
$\quad \begin{array}{l}\text { Non-EU with PIIGS } \\
\text { Non-EU with }\end{array}$ & 0.335 & 0.541 & 0.480 & $0.206^{* * *}$ & -0.061 \\
$\quad$ advanced EU & 0.447 & 0.605 & 0.602 & $0.158^{*}$ & -0.003 \\
$\quad \begin{array}{l}\text { Non-EU with non-EU } \\
\text { UK with Switzerland }\end{array}$ & 0.246 & 0.351 & 0.371 & 0.105 & 0.020 \\
\hline
\end{tabular}

***, ** * indicate statistical significance at the $0.01,0.05$ and 0.10 level, respectively.

other markets, the comovements in orthogonalized returns are lower by $15 \%$ or less relative to the comovements in raw returns. ${ }^{33}$

Interestingly, Table 11 shows that the relative structure of average comovements across time remained largely intact, albeit at a lower level. In particular, the comovements within and across the groups of countries within the EU went up with the advent of the financial crisis and went down only slightly, and insignificantly, during the recovery period. ${ }^{34}$ Thus, both cross-section and time series results with respect to

\footnotetext{
${ }^{33}$ Not surprisingly, since this exercise controls for the U.S. Fama-French factors, the changes in correlations of the United States with other countries changed much more drastically; the factor regression for the United States produces an $R^{2}$ of 0.99 .

${ }^{34}$ The results for non-EU countries are driven by the drastic changes in the U.S. correlations with other countries and show no significant changes throughout.
} 
Table 11

Controlling for Fama-French daily factors: Comovements among PIIGS (Portugal, Ireland, Italy, Greece and Spain), advanced European Union (EU), and non-EU countries during pre-crisis (January 1, 1999 to June 30, 2007), crisis (July 1, 2007 to June 30, 2009), and recovery (July 1, 2009 to November 26, 2013) periods: Average of correlations

This table explores the possibility that the Fama-French three factors may drive the observed pattern of comovements. Each country's stock market returns are orthogonalized using the daily Fama-French factors from Kenneth French's Web site (http://mba.tuck.dartmouth.edu/ pages/faculty/ken.french/data_library.html). The table reports group averages of cross-country correlations of the residuals from the Fama-French three-factor model with market portfolio return, market capitalization (SMB [small minus big]), and book-to-market (HML [high minus low]) factors. The last two columns show the difference between the crisis and pre-crisis periods and the difference between the recovery and crisis periods. The significance tests are $t$-tests for the difference in means, except for UK-Switzerland, which is done in both cases using Fisher's $z$-transform-based test as in Table 5.

\begin{tabular}{lccccc}
\hline Groups of countries & Pre-crisis & Crisis & Post-crisis & $\begin{array}{c}\text { Crisis minus } \\
\text { pre-crisis }\end{array}$ & $\begin{array}{c}\text { Post-crisis } \\
\text { minus crisis }\end{array}$ \\
\hline $\begin{array}{l}\text { PIIGS with PIIGS } \\
\text { Advanced EU with }\end{array}$ & 0.460 & 0.702 & 0.594 & $0.242^{* * *}$ & -0.109 \\
$\quad$ PIIGS & 0.567 & 0.788 & 0.701 & $0.221^{* * *}$ & $-0.087^{*}$ \\
$\begin{array}{l}\text { Advanced EU with } \\
\quad \text { advanced EU }\end{array}$ & 0.796 & 0.914 & 0.892 & $0.118^{* *}$ & -0.022 \\
$\begin{array}{l}\text { Non-EU with PIIGS } \\
\text { Non-EU with }\end{array}$ & 0.252 & 0.410 & 0.305 & $0.159^{*}$ & -0.105 \\
$\quad$ advanced EU & 0.300 & 0.446 & 0.414 & 0.146 & -0.032 \\
$\begin{array}{l}\text { Non-EU with non-EU } \\
\text { UK with Switzerland }\end{array}$ & 0.123 & 0.177 & 0.201 & 0.054 & 0.024 \\
\hline
\end{tabular}

$* * * * * * *$ indicate statistical significance at the $0.01,0.05$ and 0.10 level, respectively.

the market comovements in Europe hold when controlling for the Fama-French risk factors.

\subsection{U.S. and global factors}

Finally, we explore the possibility that U.S. and global factors may explain the observed pattern of comovements. Following Bekaert, Ehrmann, Fratzscher and Mehl (2014), each country's stock market returns are orthogonalized using a U.S.-specific factor, measured by the U.S. MSCI index, and a global factor, measured by the world MSCI index, where, as in Bekaert, Ehrmann, Fratzscher and Mehl (2014), the global factor is the residuals from regressing the world index returns on the U.S. index returns. Note that this is an extremely liberal test, as we are controlling for the market index of the United States, a world financial leader, as well as the world market index, which reflects movements of individual countries' indices. Therefore, if we find any positive correlations and any semblance of the cross-sectional or time series structure 
that we reported for the raw returns, it would be strong evidence in support of our findings.

Table 12 reports cross-country correlations of the residuals from a modified world capital-asset pricing model as in Bekaert, Ehrmann, Fratzscher and Mehl (2014) with U.S. and global factors as described above. ${ }^{35}$ Table 12 correlates the residuals from the following regressions: $R_{i, t}=\beta_{0}+\beta_{1} \cdot R_{\mathrm{US}, t}+\beta_{2} \cdot R_{\mathrm{Global}, t}+\epsilon_{t}$, where $R_{i, t}$ is country $i$ 's stock market return, $R_{\mathrm{US}, t}$ is the U.S. factor (i.e., the return on the U.S. MSCI index), and $R_{\mathrm{Global}, t}$ is the (orthogonalized) global factor (i.e., the return on the world MSCI index). In each cell, the first number is Pearson correlation coefficient, the second number is Spearman's rho, and the third number is Kendall's tau. Most coefficients are significant at the $1 \%$ level, and most correlations remain positive, with United States and Japan being notable exceptions.

Table 13 shows average Pearson correlations within and between the three groups of countries-PIIGS, advanced EU and non-EU-for the three subperiodspre-crisis, crisis, and post-crisis. As before, the last two columns show the difference between the crisis and pre-crisis periods, as well as the difference between the recovery and crisis periods. Although the statistical significance of the differences between crisis and post-crisis correlations disappears as a result of controlling for the U.S. and global factors, the relative structure of correlations and their economic significance is preserved. We find that for all six pair combinations of our three groups of countries (i.e., PIIGS with each other, advanced EU with PIIGS, advanced EU with each other, non-EU with PIIGS, non-EU with advanced EU, and non-EU with each other), the comovements increased during the crisis. Strikingly, for four of the six pairs, the (orthogonalized) comovements continued to increase during the post-crisis recovery, albeit only slightly and statistically insignificantly. Thus, even when we control for U.S. and global factors, thereby severely reducing the likelihood of the robustness of the main results, we still detect the comovements structure that we found in the raw returns data.

\subsection{Summary of robustness results}

Our robustness exercises above suggest that the cross-country comovements reported in Section 4 can be explained only partially, at best, by some of the macroeconomic and market factors. Importantly, the relative structure of the comovements, both cross-sectionally and across time, remains largely immune to including the various control variables. Several specific results emerged from our analysis. First, the comovements among the Eurozone, EU and non-EU markets in our data are found to be unrelated to the monetary policy conducted by the ECB. Second, such market

\footnotetext{
${ }^{35}$ The domestic factor in Bekaert, Ehrmann, Fratzscher and Mehl (2014)—country MSCI index—is our dependent variable.
} 


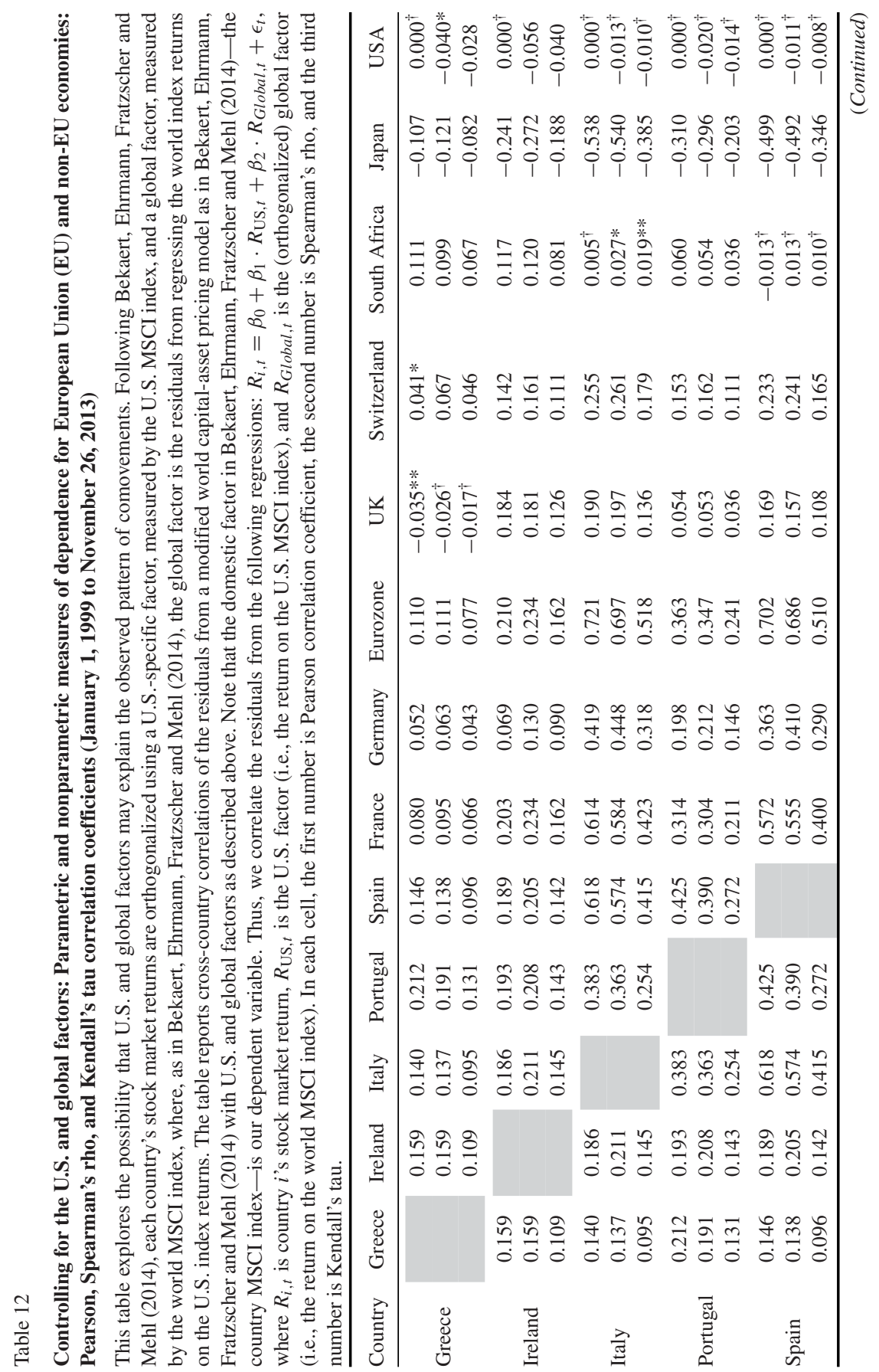




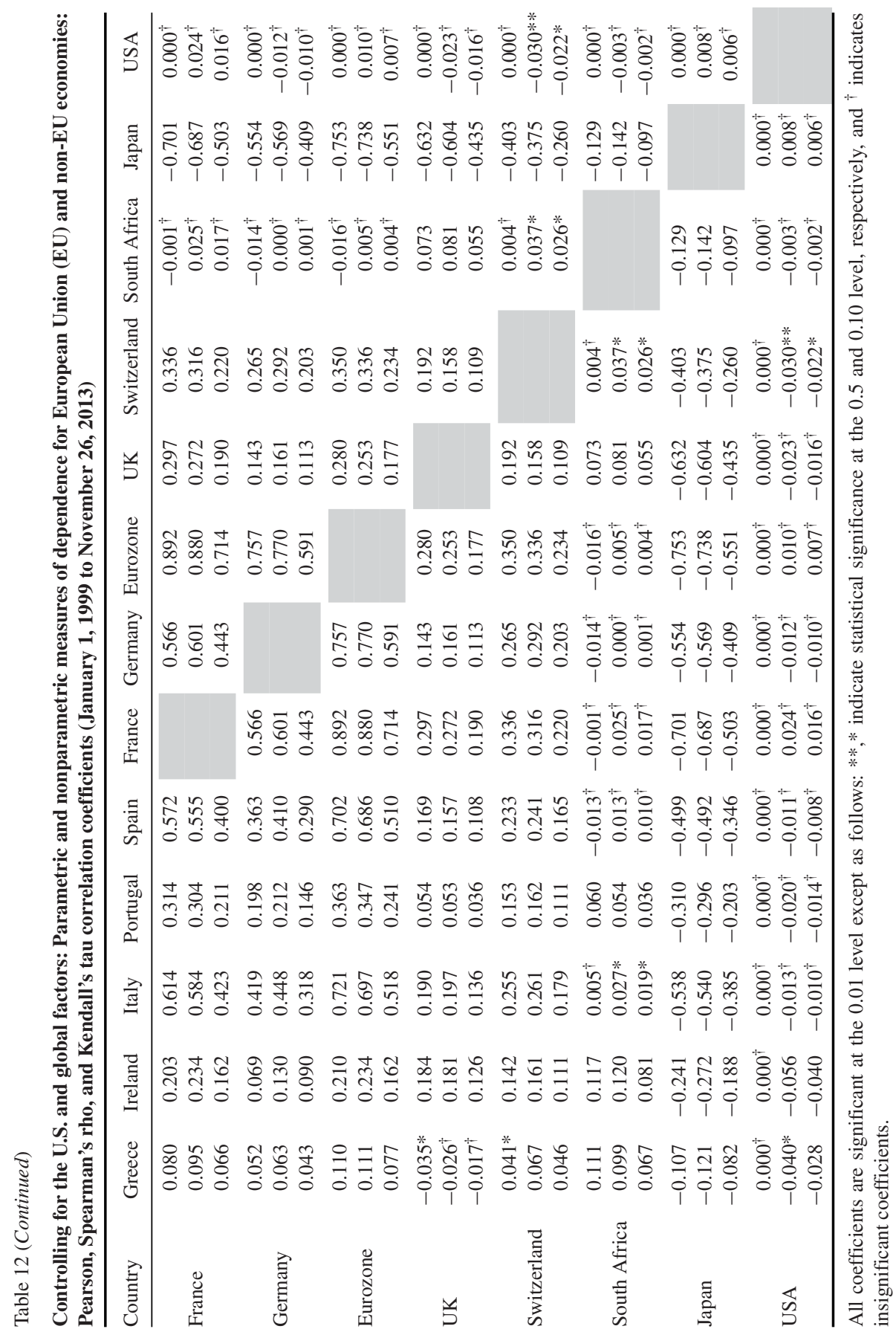


Table 13

Controlling for the U.S. and global factors: Comovements among PIIGS (Portugal, Ireland, Italy, Greece and Spain), advanced European Union (EU), and non-EU countries during pre-crisis (January 1, 1999 to June 30, 2007), crisis (July 1, 2007 to June 30, 2009), and recovery (July 1, 2009 to November 26, 2013) periods: Average correlations

This table explores the possibility that U.S. and global factors may explain the observed pattern of comovements. Following Bekaert, Ehrmann, Fratzscher and Mehl (2014), each country's stock market returns are orthogonalized using a U.S.-specific factor, measured by the U.S. MSCI index, and a global factor, measured by the world MSCI index, where, as in Bekaert, Ehrmann, Fratzscher and Mehl (2014), the global factor is the residuals from regressing the world index returns on the U.S. index returns. The table reports group averages of cross-country correlations of the residuals from a modified world capitalasset pricing model as in Bekaert, Ehrmann, Fratzscher and Mehl (2014) with U.S. and global factors as described above. Note that the domestic factor in Bekaert, Ehrmann, Fratzscher and Mehl (2014) - the country MSCI index - is our dependent variable. Thus, we correlate the residuals from the following regressions: $R_{i, t}=\beta_{0}+\beta_{1} \cdot R_{\mathrm{US}, t}+\beta_{2} \cdot R_{\text {Global }, t}+\epsilon_{t}$, where $R_{i, t}$ is country $i$ 's stock market return, $R_{\mathrm{US}, t}$ is the U.S. factor (i.e., the return on the U.S. MSCI index), and $R_{\text {Global }, t}$ is the (orthogonalized) global factor (i.e., the return on the world MSCI index). The last two columns show the difference between the crisis and pre-crisis periods and the difference between the recovery and crisis periods. The significance tests are $t$-tests for the difference in means, except for UK-Switzerland, which is done in both cases using Fisher's z-transform-based test as in Table 5.

\begin{tabular}{lccccc}
\hline Groups of countries & Pre-crisis & Crisis & Post-crisis & $\begin{array}{c}\text { Crisis minus } \\
\text { pre-crisis }\end{array}$ & $\begin{array}{c}\text { Post-crisis } \\
\text { minus crisis }\end{array}$ \\
\hline $\begin{array}{l}\text { PIIGS with PIIGS } \\
\text { Advanced EU with }\end{array}$ & 0.209 & 0.262 & 0.341 & 0.053 & 0.078 \\
$\quad$ PIIGS & 0.203 & 0.336 & 0.369 & $0.133^{*}$ & 0.033 \\
$\begin{array}{l}\text { Advanced EU with } \\
\quad \text { advanced EU }\end{array}$ & 0.434 & 0.571 & 0.548 & 0.137 & -0.023 \\
$\begin{array}{l}\text { Non-EU with PIIGS } \\
\text { Non-EU with }\end{array}$ & -0.062 & -0.007 & -0.004 & 0.055 & 0.003 \\
$\quad$ advanced EU & -0.124 & -0.071 & -0.038 & 0.052 & 0.033 \\
$\begin{array}{l}\text { Non-EU with non-EU } \\
\text { UK with Switzerland }\end{array}$ & -0.074 & -0.101 & -0.104 & -0.027 & -0.003 \\
\hline
\end{tabular}

**** ${ }^{*}$ indicate statistical significance at the 0.01 and 0.10 level, respectively.

factors as the LIBOR rate, VIX and exchange rate cannot account for the observed comovements. Third, our main results are robust to controlling for the Fama-French risk factors. Finally, although the results are weakened when U.S. and global factors are introduced as controls, we still find the same relative pattern of comovements both cross-sectionally (i.e., for the various groups of countries) and over time (i.e., for pre-crisis, crisis, and post-crisis periods). Taken together-and in light of Bekaert, Harvey and Ng's (2005) definition of contagion—our results suggest that there has been a financial contagion in Europe during the financial crisis and that the specific mechanisms behind the spread of the contagion are in line with those studied by Caporin, Pelizzon, Ravazzolo and Rigobon (2018) and Fratzscher, Lo Duca and Straub (2018) - namely, that the spread of the contagion can be partially accounted for by the linkages between European and U.S. markets. Notably, we find that the increased 
comovements are not yet a thing of the past, even when controlling for monetary policy, interest rates, exchange rates, market uncertainty, and Fama-French, U.S. and global factors. Thus, our main results with respect to the comovements structure hold across the board.

\section{Conclusions}

Using parametric, semi-parametric and nonparametric techniques, we find that stock market interdependence increased among Eurozone countries, the UK, and four non-EU countries during the global financial crisis but has not notably attenuated afterward. We examine traditional and nonlinear correlations, Student's $t$ and Gaussian copulas, as well as lower tail dependence and quantile dependence using MSCI stock indices data for the EU countries of France, Germany, the UK and the PIIGS, as well as four non-EU countries, focusing on the post-euro adoption period (January 1999 to present). All stock market returns (including major markets such as the United States, Germany, the UK, and Japan) are nonlinear, skewed, and affected to differing degrees by the financial crisis and excessive debt, and copula functions allow us to capture nonlinearities in the financial interdependence and cross-market linkages.

In contrast to some of the previous research (e.g., Herrera and Eichler, 2011), our results, based on quantile dependence and other methods, suggest relatively little interdependence between PIIGS and more financially sound economies (such as Germany, France, and the UK). We also find that the interdependence among the PIIGS economies is not as strong as that among European economies less likely to face a fiscal crisis, such as France, Germany and the UK. Although interdependencies increased during the crisis, the relative relation of lower interdependency for the PIIGS among themselves than with the more advanced markets or for the more advanced markets with each other continues to hold. These results suggest that financial interdependence may be related to the level of stock market development in various countries as proxied, for example, by market capitalization (see Table 1). We also find that the non-EU countries tend to have lower interdependencies with the EU countries. Notably for the pending Brexit, the UK appears to have greater comovements with its EU counterparts than does Switzerland, despite Switzerland sharing borders with France, Germany and Italy.

These findings are robust as they are based on several complementary methodologies - namely, linear and nonlinear correlations, copulas, quantile dependence, and lower tail dependence - and our copulas-based analysis shows that these results are largely immune to distributional assumptions of the joint density function and to using empirical marginal distributions. ${ }^{36}$ Our copula-based measures of dependence

\footnotetext{
${ }^{36}$ Our bivariate dependence measures are complementary to the copula vines approach (e.g., Kurowicka and Joe, 2010) and provide information at a more granular level: for example, the bivariate estimation results allow each country to learn which international market(s) comove most closely with the domestic market.
} 
can be used in the presence of endogeneity if (as is the case in our paper) the goal is to measure comovements without making causal statements. In addition, since our semiparametric and nonparametric methods do not hinge on rigid modeling assumptions, the methodology used in this paper circumvents the omitted variables bias.

Our results for the UK, which are similar to those for France and Germany (both in terms of comovements with PIIGS and with other advanced countries), suggest the common currency alone does not appear to be the driving factor behind the results reported in this paper. We also find that non-EU countries, including Switzerland, exhibit weaker stock market comovements with EU members as compared with the comovements among the EU nations, even in the presence of strong trade and investment interdependencies. This finding suggests that the UK should expect lower stock market comovements with other European nations if and when the country implements its exit from the EU.

Our results are also consistent with some of the most recent literature that finds no compelling evidence of financial contagion from PIIGS economies to the rest of the euro area (e.g., Bhanot, Burns, Hunter and Williams, 2012) and a lower level of financial interdependence among the PIIGS following the onset of the sovereign debt crises in Europe (e.g., Tamakoshi and Hamori, 2011). Additionally, our findings can be construed as empirical corroboration for Vasudevan's (2010) general analytical argument that indebted periphery countries can help mitigate, through capital flight, the imbalances in the international monetary system. To the extent that PIIGS countries' economic fundamentals are weaker than those in the more advanced European countries, our results can be viewed as indirectly challenging what Bekaert, Ehrmann, Fratzscher and Mehl (2014) refer to as "domestic contagion"- that is, the finding that the severity of a contagion experienced by a particular country is related to the quality of the country's economic fundamentals. They report that domestic contagion played a much more important role in the most recent financial crisis than crosscountry trade, banking or financial linkages. Instead, our results are in agreement with Dungey and Gajurel (2014), who suggest that financial contagion effects are not strongly related to a country's level of financial integration.

Our findings on the relative shift in comovement structure pre-crisis and postcrisis are new and augment those in Christoffersen, Errunza, Jacobs and Langlois (2012), who use data ending in June 2009. Since our main data sample runs through November 2013 (with the overall sample ending in September 2015), our examination of the recovery that followed the global financial crisis uncovers an interesting and important result not reported in Christoffersen, Errunza, Jacobs and Langlois (2012): namely, that the most recent financial crisis caused a permanent change in the level of stock market comovements in Europe, but the overall relative structure remained the same and was not affected by the crisis. Finally, our results on the pre-crisis vis-à-vis crisis and post-crisis comparison are in line with the literature's reports on asymmetric correlations among financial markets during bull and bear periods (e.g., Ang and Bekaert, 2002). What is new and unexpected among our findings is that the relative correlation structure among the European financial markets remained intact 
as the world economy was entering into the global financial crisis and the subsequent recovery.

Our results are of stock market comovements (or interdependence) and not of contagion per se, which is why we do not identify a specific mechanism via which a contagion may spread. ${ }^{37}$ However, our analysis is related to the contagion literature to the extent that we explicitly compare the degree of stock market comovements during the most recent financial crisis with comovements during the pre-crisis period and post-crisis recovery. The literature does not offer a consensus definition of contagion or an agreed-upon empirical procedure to identify a contagion (e.g., Forbes and Rigobon, 2002; Pericoli and Sbracia, 2003; Bekaert, Harvey and Ng, 2005). Analyses of historical crisis episodes seem to draw the least amount of skepticism with respect to contagion identification. In our study, the crisis period is also institutionally determined, as most agree on the (approximate) dates of the recent financial crisis. Among the definitions of contagion that are entertained by the literature, our analysis is closest to the definition that identifies a contagion as a significant increase in comovements following an onset of a crisis (see definition 4 surveyed by Pericoli and Sbracia, 2003). In light of the empirical literature's use of extreme negative comovements to identify crisis events (e.g., Rodriguez, 2007; Aloui, Aïssa and Nguyen, 2011), we also compute copula-based lower tail dependence coefficients and find that our results are robust to using this alternative approach.

The robustness section of the paper further adds to the contagion discussion. We show that our reported structure of comovements is largely robust to controlling for the monetary policy, interest rates, exchange rates, market uncertainty (as measured by VIX), Fama-French risk factors, and U.S. and global factors. Although residual comovements are somewhat lower than the comovements in raw returns, the paper's main results are preserved both cross-sectionally-lower comovements of the PIIGS countries with one another than with advanced EU countries and, in turn, lower PIIGS-advanced countries comovements than comovements of the EU advanced countries among themselves - and across time - an increase in comovements during the crisis without any significant reduction in the post-crisis period. Using Bekaert, Harvey and Ng's (2005) definition of contagion, our results indicate that the European stock markets experienced a financial contagion during the financial crisis and that it is too soon to speak of the comovements reverting in the direction of the precrisis levels. Our results are consistent with the specific mechanisms behind the spread of the contagion studied by Caporin, Pelizzon, Ravazzolo and Rigobon (2018) and Fratzscher, Lo Duca and Straub (2018)—namely, that the European countries' linkages with the United States played a role in the spread of contagion.

\footnotetext{
${ }^{37}$ The contagion literature has explored the portfolio rebalancing channel (e.g., Kodres and Pritsker, 2002), the wealth effect channel (e.g., Kyle and Xiong, 2001; Yuan, 2005) and the common creditor channel (e.g., Kaminsky and Reinhart, 2000; Broner, Gelos and Reinhart, 2006) of financial crisis transmission. There are also behavioral explanations, such as herd behavior, that are inherently difficult to capture in a formal framework.
} 
Our paper also has important implications for international portfolio diversification. In particular, we show that contrary to the conventional wisdom, the stock market comovements across the EU did not go down significantly in the post-crisis period. Additionally, we report that the comovements among the advanced EU countries are higher than the comovements between the advanced and peripheral economies, and that this relative structure has been preserved over time. These results cannot be attributed to the common macroeconomic, market, or Fama-French factors.

Finally, while it is impossible to predict precisely what will happen when Brexit concludes, our results may shed some light on what the UK may experience as it moves from being part of the EU to being a non-EU country. In particular, the nonEU results found that while the global structure generally remained similar, the UK's comovements with the major and minor EU countries were similar but generally stronger than those of Switzerland, a non-EU member located centrally in Europe. Therefore, as the UK leaves the EU, it is possible that its stock market comovements may become more similar to those of Switzerland.

\section{Appendix A}

Copula models allow researchers to study dependence structures of bivariate and multivariate distributions. A joint distribution function contains information on both the marginal distributions of the individual variables and the dependence structure between the variables, and copula methodology allows one to separate the marginals from the dependence structures. An $m$-dimensional copula, commonly denoted as $C\left(u_{1}, \ldots, u_{m}\right)$, is a joint distribution function on $[0,1]^{m}$ with all marginal distributions being standard uniform.

Sklar's (1959) theorem provides the theoretical underpinnings for most copulabased analyses. Let $F$ be a joint distribution function and $F_{j}, j=1, \ldots, m$ be the marginal distributions. Then there exists a copula $C:[0,1]^{m} \rightarrow[0,1]$ such that $F\left(x_{1}, \ldots, x_{m}\right)=C\left(F_{1}\left(x_{1}\right), \ldots, F_{m}\left(x_{m}\right)\right)$ for all $x_{1}, \ldots, x_{m}$ in $[-\infty, \infty]$. If the marginals are continuous, $C$ is unique. Otherwise, $C$ is uniquely determined on $\operatorname{Ran} F_{1} \times \ldots \times \operatorname{Ran} F_{m}$, where $\operatorname{Ran} F_{j}=F_{j}([-\infty, \infty])$ is the range of $F_{j}$. Conversely, if $C$ is a copula and $F_{1}, \ldots, F_{m}$ are univariate distribution functions, then $F\left(x_{1}, \ldots, x_{m}\right)$ is a joint distribution function with marginal distributions $F_{j}$, $j=1, \ldots, m$. Thus, Sklar's (1959) theorem claims that (1) a copula can be derived from any joint distribution functions, and (2) any copula can be combined with any set of marginal distributions to produce a multivariate distribution function. Put simply, copulas join (or "couple") marginal distributions into a joint distribution.

Stock returns for each country are transformed into the uniform $[0,1]$ distribution using the probability integral transformation $\int_{-\infty}^{+\infty} p(x) d x=1$, where $p(x)$ is the probability of $x$. Next, suppose $y$ is related to $x$ such that $y=\int_{-\infty}^{x} p(x) d x$, where $y$ is an ordered function of $x$ and $0<y<1$. Then $p(x)=p(y) \frac{d x}{d y}=1$. Given uniform [0,1] distributions $u$ and $v$ for data series $x$ and $y$, respectively, 
$C(u, v)=F_{x y}\left(F_{x}^{-1}(u), F_{y}^{-1}(v)\right)$, where $C(u, v)$ is the copula, $F_{x y}$ is the joint cumulative density function, and $F_{x}^{-1}$ and $F_{y}^{-1}$ are the inverse rank order functions (Skoglund, 2010). The copula estimates are computed for a given joint cumulative density function. Below, we discuss the types of copulas and dependence measures used in our analysis.

\section{A.1. Gaussian normal copula}

We begin with a copula based on the Gaussian Normal distribution. Let $u_{j} \sim$ $U(0,1)$ for $j=1, \ldots, m$, where $U(0,1)$ represents the uniform distribution on the $[0,1]$ interval. Let $\sum$ be the positive semidefinite correlation matrix with $m(m-1) / 2$ parameters. The Gaussian Normal copula can be written as

$$
C_{\Sigma}\left(u_{1}, u_{2}, \ldots, u_{m}\right)=\Phi_{\Sigma}\left(\Phi^{-1}\left(u_{1}\right), \Phi^{-1}\left(u_{2}\right), \ldots, \Phi^{-1}\left(u_{m}\right)\right),
$$

where $\Phi$ is the distribution function of a standard normal random variable and $\Phi_{\Sigma}$ is the $m$-variate standard normal distribution with mean vector 0 and covariance matrix $\Sigma$. That is, the distribution $\Phi_{\Sigma}$ is $N_{m}(0, \Sigma)$.

\section{A.2. Student's t copula}

We next turn to a copula based on the Student's $t$ distribution. Specifically, let $\Theta=\left\{(v, \Sigma): v \in(1, \infty), \Sigma \in \mathbb{R}^{m \times m}\right\}$ and let $t_{v}$ be a univariate $t$ distribution with $v$ degrees of freedom. The Student's $t$ copula can be written as

$$
C_{\Theta}\left(u_{1}, u_{2}, \ldots, u_{m}\right)=\mathbf{t}_{v, \Sigma}\left(t_{v}^{-1}\left(u_{1}\right), t_{v}^{-1}\left(u_{2}\right), \ldots, t_{v}^{-1}\left(u_{m}\right)\right),
$$

where $\mathbf{t}_{v, \Sigma}$ is the multivariate Student's $t$ distribution with a correlation matrix $\Sigma$ and $v$ degrees of freedom.

\section{A.3. Archimedean copulas}

We next turn to three types of Archimedean copulas examined for our analyses: Clayton, Frank, and Gumbel. Let function $\phi:[0,1] \rightarrow[0, \infty)$ be a strict Archimedean copula generator function, and assume that $\phi$ is decreasing and that $\phi^{-1}$ is completely monotonic on $[0, \infty) .{ }^{38}$ In general, an Archimedean copula (Clayton, Frank or Gumbel) is defined as

$$
C\left(u_{1}, u_{2}, \ldots, u_{m}\right)=\phi^{-1}\left(\phi\left(u_{1}\right), \phi\left(u_{2}\right), \ldots, \phi\left(u_{m}\right)\right) .
$$

\footnotetext{
${ }^{38} \mathrm{~A}$ strict generator is a decreasing function $\phi:[0,1] \rightarrow[0, \infty)$ such that $\phi(0)=\infty$ and $\phi(1)=0$. A decreasing function $f(t):[a, b] \rightarrow(-\infty, \infty)$ is completely monotonic if

$$
(-1)^{k} \frac{d^{k}}{d t^{k}} f(t) \geq 0, k \in \mathbb{N}, t \in(a, b) .
$$
}




\section{Clayton copula}

Let the generator function $\phi(u)=\theta^{-1}\left(u^{-\theta}-1\right)$. A Clayton copula is defined as

$$
C_{\theta}\left(u_{1}, u_{2}, \ldots, u_{m}\right)=\left[\sum_{i=1}^{m} u_{i}^{-\theta}-m+1\right]^{-\frac{1}{\theta}}
$$

with $\theta>0$.

\section{Frank copula}

With the generator function $\phi(u)=-\log \left[\frac{e^{-\theta u}-1}{e^{-\theta}-1}\right]$, a Frank copula is defined as

$$
C_{\theta}\left(u_{1}, u_{2}, \ldots, u_{m}\right)=\frac{1}{\theta} \log \left[1+\frac{\prod_{i=1}^{m}\left(e^{-\theta u_{i}}-1\right)}{\left(e^{-\theta}-1\right)^{m-1}}\right]
$$

with $\theta \in(-\infty, \infty) \backslash\{0\}$ for $m=2$ and $\theta>0$ for $m \geq 3$.

\section{Gumbel copula}

Finally, if the generation $\phi(u)=(-\log (u))^{\theta}$, a Gumbel copula is defined as

$$
C_{\theta}\left(u_{1}, u_{2}, \ldots, u_{m}\right)=\exp \left[-\left[\sum_{i=1}^{m}\left(-\log \left(u_{i}\right)\right)^{\theta}\right]^{\frac{1}{\theta}}\right]
$$

with $\theta>1$ (see, e.g., SAS Institute Inc., 2011).

A.3.1. Measure of concordance. Kendall's tau can be defined as the covariance between the sign statistic of $X_{1}-\tilde{X}_{1}$ and $X_{2}-\tilde{X}_{2}$, where $\left(\tilde{X}_{1}, \tilde{X}_{2}\right)$ is an independent copy of $\left(X_{1}, X_{2}\right)$ :

$$
\rho_{\tau} \equiv E\left[\operatorname{sign}\left(X_{1}-\tilde{X}_{1}\right)\left(X_{2}-\tilde{X}_{2}\right)\right]
$$

Spearman's rho is the correlation between the transformed random variables, which (after the transformation by their distribution functions) are uniformly distributed on $[0,1]$ :

$$
\rho_{S}\left(X_{1}, X_{2}\right) \equiv \rho\left(F_{1}\left(x_{1}\right), F_{2}\left(x_{2}\right)\right) .
$$

Thus, if $X_{1}$ and $X_{2}$ cluster around any monotonically increasing function, both Kendall's tau and Spearman's rho will register a rank correlation of 1 . In contrast, a Pearson coefficient will register a perfect correlation only if $X_{1}$ and $X_{2}$ cluster around an increasing linear function.

A.3.2. Quantile dependence. Quantile dependence allows us to measure comovements for various return quantiles. Following Patton (2012), we define lower quantile dependence as

$$
\lambda_{q}^{L}=\operatorname{Pr}\left(U_{1} \leq q, U_{2} \leq q\right) / q, \quad q \in(0,0.5]
$$


and upper quantile dependence as

$$
\lambda_{q}^{U}=\operatorname{Pr}\left(U_{1}>q, U_{2}>q\right) /(1-q), \quad q \in[0.5,1) .
$$

A.3.3. Lower and upper tail dependence. If $(X, Y)$ is a vector of random variables with marginal distribution functions $F$ and $G$ such that $F^{-1}(t)=x(t)$ and $G^{-1}(t)=$ $y(t)$, then lower tail dependence $\lambda_{C}^{L}$ is defined as

$$
\lambda_{C}^{L}=\lim _{t \rightarrow 0^{+}} \operatorname{Pr}[Y \leq y(t) \mid X \leq x(t)]
$$

This measure of extreme negative comovements depends only on the copula of the two variables and can be computed as

$$
\lambda_{C}^{L}=\lim _{t \rightarrow 0^{+}} \frac{C(t, t)}{t}=\delta_{C}^{\prime}\left(0^{+}\right),
$$

where $\delta_{C}^{\prime}(t)$ is the derivative of the copula's diagonal (Nelsen, 2006). In our computation of $\lambda_{C}^{L}$, we rely on empirical copulas. $\lambda_{C}^{L}=0$ would indicate no lower tail dependence. The higher the $\lambda_{C}^{L}$, the greater the extreme negative comovements.

For completeness, we also study the upper tail dependence $\lambda_{C}^{U}$, which is defined and computed similarly to $\lambda_{C}^{L}$ :

$$
\lambda_{C}^{U}=\lim _{t \rightarrow 1^{-}} \operatorname{Pr}[Y>y(t) \mid X>x(t)]
$$

and

$$
\lambda_{C}^{U}=\lim _{t \rightarrow 1^{-}} \frac{1-2 t-C(t, t)}{1-t}=2-\delta_{C}^{\prime}\left(1^{-}\right)
$$

(see, e.g., Nelsen, 2006; Joe, 2014).

\section{References}

Aloui, R., M.S.B. Aïssa, and D.K. Nguyen, 2011. Global financial crisis, extreme interdependences, and contagion effects: The role of economic structure? Journal of Banking and Finance 35(1), 130-141.

Aloui, R., M.S.B. Aïssa, and D.K. Nguyen, 2013. Conditional dependence structure between oil prices and exchange rates: A copula-GARCH approach, Journal of International Money and Finance 32, 719-738.

Ang, A. and G. Bekaert, 2002. International asset allocation with regime shifts, Review of Financial Studies 15(4), 1137-1187.

Baele, L., 2005. Volatility spillover effects in European equity markets, Journal of Financial and Quantitative Analysis 40(2), 373-401.

Bartram, S.M., S.J. Taylor, and Y.-H. Wang, 2007. The euro and European financial market dependence, Journal of Banking and Finance 31(5), 1461-1481.

Bekaert, G., M. Ehrmann, M. Fratzscher, and A. Mehl, 2014. The global crisis and equity market contagion, Journal of Finance 69(6), 2597-2649.

Bekaert, G., C.R. Harvey, and A. Ng, 2005. Market integration and contagion, Journal of Business 78(1), 39-69.

Bekaert, G., R.J. Hodrick, and X. Zhang, 2009. International stock return comovements, Journal of Finance 64(6), 2591-2626. 
Bhanot, K., N. Burns, D. Hunter, and M. Williams, 2012. Was there contagion in Eurozone sovereign bond markets during the Greek debt crisis? Working paper, University of Texas at San Antonio.

Boyson, N.M., C.W. Stahel, and R.M. Stulz, 2010. Hedge fund contagion and liquidity shocks, Journal of Finance 65(5), 1789-1816.

Broner, F.A., R.G. Gelos, and C.M. Reinhart, 2006. When in peril, retrench: Testing the portfolio channel of contagion, Journal of International Economics 69(1), 203-230.

Caporin, M., L. Pelizzon, F. Ravazzolo, and R. Rigobon, 2018. Measuring sovereign contagion in Europe, Journal of Financial Stability 34, 150-181.

Chollete, L., V. de la Peña, and C.-C. Lu, 2011. International diversification: A copula approach, Journal of Banking and Finance 35(2), 403-417.

Chollete, L., A. Heinen, and A. Valdesogo, 2009. Modeling international financial returns with a multivariate regime-switching copula, Journal of Financial Econometrics 7(4), 437-480.

Christoffersen, P., V. Errunza, K. Jacobs, and H. Langlois, 2012. Is the potential for international diversification disappearing? A dynamic copula approach, Review of Financial Studies 25(12), 3711-3751.

Chui, A.C.W., S. Titman, and K.C.J. Wei, 2010. Individualism and momentum around the world, Journal of Finance 65(1), 361-392.

Chvosta, J., D.J. Erdman, and M. Little, 2011. Modeling financial risk factor correlation with the COPULA procedure. SAS Global Forum, Paper 340-2011, SAS Institute Inc., Cary, NC.

de Haan, L. and A. Ferreira, 2006. Extreme Value Theory: An Introduction (Springer, New York).

Dungey, M. and D. Gajurel, 2014. Equity market contagion during the global financial crisis: Evidence from the world's eight largest economies, Economic Systems 38(2), 161-177.

Favero, C. and F. Giavazzi, 2002. Is the international propagation of financial shocks non-linear? Evidence from the ERM, Journal of International Economics 57, 231-246.

Fernández-Avilés, G., J.-M. Montero, and A.G. Orlov, 2012. Spatial modeling of stock market comovements, Finance Research Letters 9(4), 202-212.

Forbes, K.J. and R. Rigobon, 2002. No contagion, only interdependence: Measuring stock market comovements, Journal of Finance 57(5), 2223-2261.

Fratzscher, M., M. Lo Duca, and R. Straub, 2018. On the international spillovers of US quantitative easing, Economic Journal 128(608), 330-377.

Herrera, R. and S. Eichler, 2011. Extreme dependence with asymmetric thresholds: Evidence for the European Monetary Union, Journal of Banking and Finance 35(11), 2916-2930.

Joe, H., 2014. Dependence Modeling with Copulas (CRC Press, Boca Raton, FL).

Kaminsky, G.L. and C.M. Reinhart, 2000. On crises, contagion, and confusion, Journal of International Economics 51(1), 145-168.

King, M.A. and S. Wadhwani, 1990. Transmission of volatility between stock markets, Review of Financial Studies 3(1), 5-33.

Kodres, L.E. and M. Pritsker, 2002. A rational expectations model of financial contagion, Journal of Finance 57(2), 769-799.

Kurowicka, D. and H. Joe, 2010. Dependence Modeling: Vine Copula Handbook (World Scientific, London).

Kyle, A.S. and W. Xiong, 2001. Contagion as a wealth effect, Journal of Finance 56(4), 1401-1440.

Longin, F. and B. Solnik, 2001. Extreme correlation of international equity markets, Journal of Finance 56(2), 649-676.

Lucas, A., B. Schwaab, and X. Zhang, 2014. Conditional euro area sovereign default risk, Journal of Business and Economic Statistics 32(2), 271-284.

Maxfield, J., 2013. A timeline of Bear Stearns' downfall. http://www.fool.com/investing/ general/2013/03/15/a-timeline-of-bear-stearns-downfall.aspx

Mendoza, E.G. and V. Quadrini, 2010. Financial globalization, financial crises and contagion, Journal of Monetary Economics 57(1), 24-39.

Morck, R., B. Yeung, and W. Yu, 2000. The information content of stock markets: Why do emerging markets have synchronous stock price movements? Journal of Financial Economics 58(1-2), 215-260. 
Nelsen, R.B., 2006. An Introduction to Copulas (Springer, New York).

Oh, D.H and A.J. Patton, 2017. Modeling dependence in high dimensions with factor copulas, Journal of Business and Economic Statistics 35(1), 139-154.

Okimoto, T., 2008. New evidence of asymmetric dependence structures in international equity markets, Journal of Financial and Quantitative Analysis 43(3), 787-815.

Okimoto, T., 2014. Asymmetric increasing trends in dependence in international equity markets, Journal of Banking and Finance 46, 219-232.

Papoulis, A., 1990. Probability and Statistics (Prentice-Hall, New York).

Patton, A.J., 2006. Modelling asymmetric exchange rate dependence, International Economic Review 47(2), 527-556.

Patton, A.J., 2012. A review of copula models for economic time series, Journal of Multivariate Analysis 110, 4-18.

Pericoli, M. and M. Sbracia, 2003. A primer on financial contagion, Journal of Economic Surveys 17(4), 571-608.

Phylaktis, K and L. Xia, 2009. Equity market comovement and contagion: A sectoral perspective, Financial Management 38(2), 381-409.

Poon, S.-H., M. Rockinger, and J. Tawn, 2004. Extreme value dependence in financial markets: Diagnostics, models, and financial implications, Review of Financial Studies 17(2), 581-610.

Reboredo, J.C. and A. Ugolini, 2015. Systemic risk in European sovereign debt markets: A CoVaR-copula approach, Journal of International Money and Finance 51, 214-244.

Rodriguez, J.C., 2007. Measuring financial contagion: A copula approach, Journal of Empirical Finance 14(3), 401-423.

SAS Institute Inc., 2011. SAS/ETS 9.3 User's Guide (SAS Institute Inc., Cary, NC).

Sklar, A., 1959. Fonctions de répartition à n dimensions et leurs marges, Publications de l'Institut de Statistique de L'Université de Paris 8, 229-231.

Skoglund, J., 2010. Risk aggregation and economic capital. White paper, SAS Institute Inc.

Solnik, B., 1974. Why not diversify internationally rather than domestically? Financial Analyst Journal 30(4), 48-54.

Stubbington, T., M. Zeng, and L. Wei, 2015. Central banks' shock therapy has investors on edge, Wall Street Journal, December 27. http://www.wsj.com/articles/central-banks-shock-therapy-has-investorson-edge-1451212203

Tamakoshi, G. and S. Hamori, 2011. Transmission of stock prices amongst European countries before and during the Greek sovereign debt crisis, Economics Bulletin 31(4), 3339-3353.

The Economist, 2016. A background guide to "Brexit" from the European Union. http://www. economist.com/blogs/graphicdetail/2016/02/graphics-britain-s-referendum-eu-membership

Vasudevan, R., 2010. Financial intermediation and fragility: The role of the periphery, International Review of Applied Economics 24(1), 57-74.

Yuan, K., 2005. Asymmetric price movements and borrowing constraints: A rational expectations equilibrium model of crises, contagion, and confusion, Journal of Finance 60(1), 379-411. 